\title{
Pseudodynamic Source Characterization for Strike-Slip Faulting Including Stress Heterogeneity and Super-Shear Ruptures
}

\author{
by B. Mena, L. A. Dalguer, and P. M. Mai
}

\begin{abstract}
Reliable ground-motion prediction for future earthquakes depends on the ability to simulate realistic earthquake source models. Though dynamic rupture calculations have recently become more popular, they are still computationally demanding. An alternative is to invoke the framework of pseudodynamic (PD) source characterizations that use simple relationships between kinematic and dynamic source parameters to build physically self-consistent kinematic models. Based on the PD approach of Guatteri et al. (2004), we propose new relationships for PD models for moderate-to-large strike-slip earthquakes that include local supershear rupture speed due to stress heterogeneities. We conduct dynamic rupture simulations using stochastic initial stress distributions to generate a suite of source models in the magnitude $M_{\mathrm{w}} 6-8$. This set of models shows that local supershear rupture speed prevails for all earthquake sizes, and that the local rise-time distribution is not controlled by the overall fault geometry, but rather by local stress changes on the faults. Based on these findings, we derive a new set of relations for the proposed PD source characterization that accounts for earthquake size, buried and surface ruptures, and includes local risetime variations and supershear rupture speed. By applying the proposed PD source characterization to several well-recorded past earthquakes, we verify that significant improvements in fitting synthetic ground motion to observed ones is achieved when comparing our new approach with the model of Guatteri et al. (2004). The proposed PD methodology can be implemented into ground-motion simulation tools for more physically reliable prediction of shaking in future earthquakes.
\end{abstract}

\section{Introduction}

Standard practice in ground-motion simulation uses kinematic rupture models for which an inhomogeneous slip distribution is prescribed (e.g., Aaagard et al., 2008). Some of these models consider also heterogeneous rise time and rupture speed. This parameterization is sometimes guided by simple theory, subjected to empirical adjustments (e.g., Graves and Pitarka, 2010), and/or source inversions (slip images) from past earthquakes. In these kinematic rupture models, the earthquake source process is associated with a prescribed spatiotemporal evolution of the slip field without taking into account the physics involved in the rupture, that is, the acting stresses and underlying constitutive relation that cause the motions. Such kinematic models do not contain the essential physics of earthquake rupture; consequently, their results may not be consistent with our understanding of fault friction and causality. Hence, this approach is expected to have limitations for predicting reliable ground motions.

In contrast, dynamic models investigate the physical processes involved in the fault rupture that usually idealize the earthquake as a dynamically running shear crack on a frictional interface embedded in a linearly elastic continuum.
This idealization has proven to be a useful foundation for analyzing natural earthquakes (e.g., Andrews, 1976a,b; Das and Aki, 1977; Day, 1982a,b; Olsen et al., 1997; Dalguer et al., 2008). These models use laboratory-based constitutive laws that govern the interface sliding during an earthquake, represented as friction models (e.g., Dieterich, 1979; Ruina, 1983; Ohnaka et al., 1987), to calculate fault rupture and slip based on assumed fault geometry, material properties, and initial stress distribution. Assuming that these initial assumptions and the friction law are realistic, the result will be physically plausible. Despite recent increases in computer power and advanced computational techniques that facilitate dynamic rupture simulations even for large earthquakes, these physical models are still not adequate for routine application of ground-motion simulation due to the high computational demands (e.g., Day et al., 2005). Moreover, site-specific seismic hazard analysis may require the consideration of a large number of earthquake scenarios in a wide magnitude range, thus further increasing the hardware requirements. An alternative to such extensive ground-motion simulations based on dynamic rupture models is therefore to 
use kinematic modeling approaches that mimic dynamic source effects.

The pseudodynamic (PD) model appears to be an elegant approach to build dynamically consistent kinematic models. Derived from analyzing dynamic source models, a PD approach aims to develop simple relationships between kinematic and dynamic source parameters, which in return can be used for ground-motion simulation. Based on this idea, there have been some attempts to build forward PD methodologies (e.g., Guatteri et al., 2004; Schmedes et al., 2010; Song and Somerville, 2010). A PD source characterization, which is based on rupture physics, may also present a convenient framework to introduce physical constraints into kinematic inversion models and ground-motion simulation tools.

The first PD source characterization was presented by Mai et al. (2001), investigating relationships between dynamic and kinematic source parameters to develop approximations that may adequately describe dynamic rupture without having to carry out full dynamic simulations. Guatteri et al. (2003) derived a methodology to include variability in the rupture-time distribution in kinematic models by generalizing results of Andrews (1976). Guatteri et al. (2004) (hereafter, G04) then defined a PD source characterization that starts with generating a slip distribution as a spatial random field (Mai and Beroza, 2002) from which the static stress-drop distribution is computed using Andrews (1980) and Ripperger et al. (2007). The resulting heterogeneous stress field is then used to estimate the temporal evolution of slip along the fault plane, allowing for some variation in rupture speed and rise time, and defining a simplified Kostrovlike source-time function.

The G04 method is based on a dataset of dynamic models that rupture up to $30 \mathrm{~km}$ fault length, resulting in $M_{\mathrm{w}} 6 \sim 7$ earthquakes. Although the G04 approach provides all the necessary steps from slip/stress distributions to the estimation of the temporal evolution of slip, the methodology has not been extensively tested and validated for ground-motion simulations.

Our study starts with calculating PD source models using the G04 method for several well-recorded past earthquakes and simulating the resulting near-field ground motions. For the validation tests, we included earthquakes both within and outside the magnitude range of the G04 method. The G04 method has limitations to produce reliable groundmotion synthetics that fit observations for longer ruptures ( $L>30 \mathrm{~km}$ ), that is, events outside the original magnitude range. Based on the comparisons of the PD simulations and the recorded ground motions, we establish the potential problems that likely cause insufficient simulation results. The G04 method validation tests provide the basis for the need of new relationships to expand the application of the PD approach proposed by G04.

In the second part of this paper, we carry out a new set of dynamic rupture simulations for many realizations of heterogeneous initial stress fields over a wide range of rupture lengths ( $L \leq 100 \mathrm{~km}$ ), resulting in $M_{\mathrm{w}} 6 \sim 8$ strike-slip earthquakes. We perform fully dynamic spontaneous rupture simulations, applying the staggered-grid split node (SGSN) method developed by Dalguer and Day (2007). The new dynamic rupture dataset provides the basis for our new PD relations and allows us to investigate sets of equations for different rupture lengths and for buried $(L \leq 35 \mathrm{~km})$ and surface-rupturing $(L \leq 35 \mathrm{~km})$ events. Dynamic models are generated with a uniform random initial stress distribution similar to Ripperger et al. (2007). We then investigate the local slip-rate functions at every point along the fault plane and analyze the parameterization of slip-rate functions within the asperities (high slip patches) as well as in the surrounding background areas (low slip areas). We examine the local rupture speeds for all sets of events having short to long rupture lengths, and characterize the localized supershear rupture behavior and its relation with the stress parameters (i.e., initial stress, stress drop, strength excess). It is important to point out that complex fault geometry may add additional effects (e.g., Oglesby and Mai, 2012) to such empirical relationships; in this study, we do not consider complex geometry and defer that for future work.

Somerville and Graves (2003) and Kagawa et al. (2004) indicate generic ground-motion differences between buried $\left(M_{\mathrm{w}}<7.2\right)$ and surface-rupturing $\left(M_{\mathrm{w}}>7.2\right)$ earthquakes. Likewise, our numerical experiments of spontaneous dynamic rupture simulations show systematic changes in source parameterization for buried and surface-breaking events. As a result of the analysis of dynamic rupture models, we introduce an entirely new set of PD relations for the characterization of the slip-rate function, its parameterization (e.g., rise time), and the rupture-velocity distribution for buried and surface-rupturing events. Finally, we carry out validation tests for the new PD relations to capture earthquake source complexity and to simulate ground motions for several recorded earthquakes, which are then compared with recorded ground motions. Our results are promising for a new PD methodology to simulate ground motions for moderate-to-large earthquakes.

\section{Ground Motions Generated by the G04 Method}

Before considering any changes in the proposed PD source characterization, we first apply the existing methodology for a number of earthquakes for which slip inversion models and sufficient number of near-field recordings are available. The G04 method starts with generating a stochastic slip distribution using spatial random fields, for chosen earthquake size, fault dimensions, and determined hypocenter. Then the static stress drop associated with the random slip distribution is computed to estimate additional kinematic source parameters. In the validation exercise, we replace the first step and utilize published slip models rather than performing stochastic slip generation. Note that we do not use the inverted rise time or rupture times, but apply the PD 
relations to generate the rupture-time and rise-time distributions. The next steps are exactly followed as in G04.

Four earthquakes have been chosen for the G04 method validation tests: the 1979 Imperial Valley earthquake $\left(M_{\mathrm{w}} 6.5\right)$, the 1989 Loma Prieta earthquake $\left(M_{\mathrm{w}} 6.8\right)$, the 2000 Tottori earthquake $\left(M_{\mathrm{w}}\right.$ 6.9), and the 1999 Izmit earthquake $\left(M_{\mathrm{w}} 7.5\right)$. The selected earthquakes cover a magnitude range beyond the range of events used to develop the G04 relations, enabling us to detect the limitations of the G04 method and to suggest further improvements to source parameter relationships. For the Imperial Valley earthquake we utilize three kinematic slip models; Archuleta (1984), Zeng and Anderson (2000), and Hartzell and Heaton (1983). Two of these models, the Zeng and Anderson (2000) model and the Hartzel and Heaton (1983) model, are slip inversions, while the model of Archuleta (1984) is generated by forward modeling. For the Tottori earthquake, we use two slip inversions: Monelli et al. (2009) and Iwata and Sekiguchi (2001). For the Loma Prieta earthquake, we choose three slip inversion models: Beroza (1991), Wald et al. (1991), and Zeng and Anderson (2000). For the Izmit earthquake, we deploy the slip inversion model of Yagi and Kikuchi (2000). The inverted slip models as well as the metadata of the four selected events are taken from the finite-source rupture model database (see Data and Resources). When choosing slip inversion models among the available ones, we give priority to the models that combine different datasets (strong ground motion, teleseismic data, GPS data, or other geodetic data). For each of the selected earthquakes, we choose at least one slip inversion that has been derived using a combination of different datasets. For instance, the inversion of Hartzel and Heaton (1983) uses strong ground-motion data and teleseismic data. Monelli et al. (2009) uses strong-motion data and GPS data. The model of Wald et al. (1991) uses a combination of strong groundmotion data, teleseismic data, and GPS data. Yagi and Kikuchi (2000) inversion uses strong ground-motion data and teleseismic data.

Based on the above-mentioned slip models, we first develop the PD source characterization using the G04 method for the four selected earthquakes. Using these PD source models, we then simulated the ground motions at the selected near-field sites, where recorded ground motions are available.

The simulations are performed with the frequencywavenumber integration code COMPSYN (Spudich and Xu, 2003) that computes seismograms for an extended source, embedded in 1D velocity density structures. We apply a triangular slip-rate function in the COMPSYN simulations for the G04 method validation tests.

For the Green's function computation of the 1979 Imperial Valley earthquake, we utilize the velocity structure given by Fuis et al. (1981a,b). For the simulation of the 1989 Loma Prieta earthquake, we apply the velocity model from Wald et al. (1991) obtained from $P$-wave velocities given by Dietz and Ellsworth (1990). The 2000 Tottori earthquake simulations are performed using the velocity structure given by Semmane et al (2005). Finally, for the 1999 Izmit earthquake, we utilize the velocity structure given by Yagi and Kikuchi (2000).

Recorded data have been obtained from the Next Generation Attenuation (NGA) and the Pacific Earthquake Engineering Research Center (PEER) databases. The level of fit between simulated and observed waveforms is computed for the velocity time histories using the following misfit function:

$$
\sum \mathrm{res}=\frac{\sum_{i=1}^{N}\left(\mathrm{obs}_{i}-\operatorname{sim}_{i}\right)^{2}}{\sqrt{\sum_{i=1}^{N} \mathrm{obs}_{i}^{2} \sqrt{\sum_{i=1}^{N} \operatorname{sim}_{i}^{2}}}}
$$

where obs is the observed time history, sim is the simulated time history, and res is the sum of the residuals. For the misfit calculation, both the observed and the simulated waveforms are band-pass-filtered between 0.1 and $1 \mathrm{~Hz}$.

\section{Rise-Time Parameterization}

In the G04 method, the rise time is mainly controlled by the total rupture duration of the fault. Rise time is parameterized by the difference between the total fault rupture duration $\left(\tau_{\text {totrup }}\right)$ and the corresponding rupture-time value $\left(T_{\text {rup }}\right)$. The total fault rupture duration is the maximum rupture-time value within the fault-boundary locations aligned with the hypocenter in either dip or strike direction. G04 proposes a linear relation for the rise-time prediction using this parameterization. As expected, $\tau_{\text {totrup }}$ increases with rupture length, and $T_{\text {rup }}$ is minimum at the hypocenter. Therefore, $\left[\tau_{\text {totrup }}-T_{\text {rup }}\right]$ takes the largest values at points close to the hypocenter. This results in large values of rise time concentrated around the hypocenter for long rupturing earthquakes. These features are related to earthquake size, but the method does not take into account the effect of local stress concentrations (asperities) due to stress heterogeneity. We will analyze the effects of this rise-time parameterization on the ground-motion simulations in the validation tests.

\section{Rupture-Speed Distribution}

The G04 method specifies variability in the rupture-time distribution based on the analytical formulation of Andrews (1976a), which relates rupture speed to fracture energy, stress drop, and crack length. This formulation considers earthquakes in the regime of subshear rupture propagation; consequently the possibility of supershear rupture speed is ignored in the G04 method. However, physics-based models (e.g, Andrews, 1976b) and observational evidence suggest that supershear ruptures are possible, especially for large strike-slip events. The first supershear rupture inferred from observations was reported for the 1979 Imperial Valley earthquake (Archuleta, 1984; Spudich and Cranswick, 1984). Subsequently, a number of large strike-slip earthquakes appeared to rupture with supershear velocity (Dunham, 2007; Bizzarri and Spudich, 2008). Therefore, it is evident 
that new PD models require source parameter relationships that take into account supershear rupture speed. Note that the rise-time calculation in the G04 method makes use of the rupture times at each point on the fault plane; consequently, the consideration of physically plausible rupture-speed distributions will also contribute to a better rise-time prediction.

\section{Validation Tests for the G04 Method}

In the following, we present ground-motion simulations and their comparison with observations for four well-recorded past earthquakes to which we apply the PD approach. Figure 1 displays PD source characterization for the $M_{\mathrm{w}} 6.9$ Tottori earthquake, computed based on the slip inversions of Iwata and Sekiguchi (2001) and Monelli et al. (2009). Figure 2 shows the PD models for the 1989 Loma Prieta earthquake of $M_{\mathrm{w}} 6.9$ based on the slip inversions of Beroza (1991), Wald et al. (1991), and Zeng and Anderson (2000). Figure 3 shows the PD models for the 1979 Imperial Valley earthquake of $M_{\mathrm{w}} 6.5$ for which three different slip inversions have been utilized: the models of Archuleta (1984), Hartzell and Heaton (1983), and Zeng and Anderson (2000). The 1999 Izmit earthquake PD source model is shown in Figure 4. Top panels of Figures 1 to 4 display the published slip distributions.
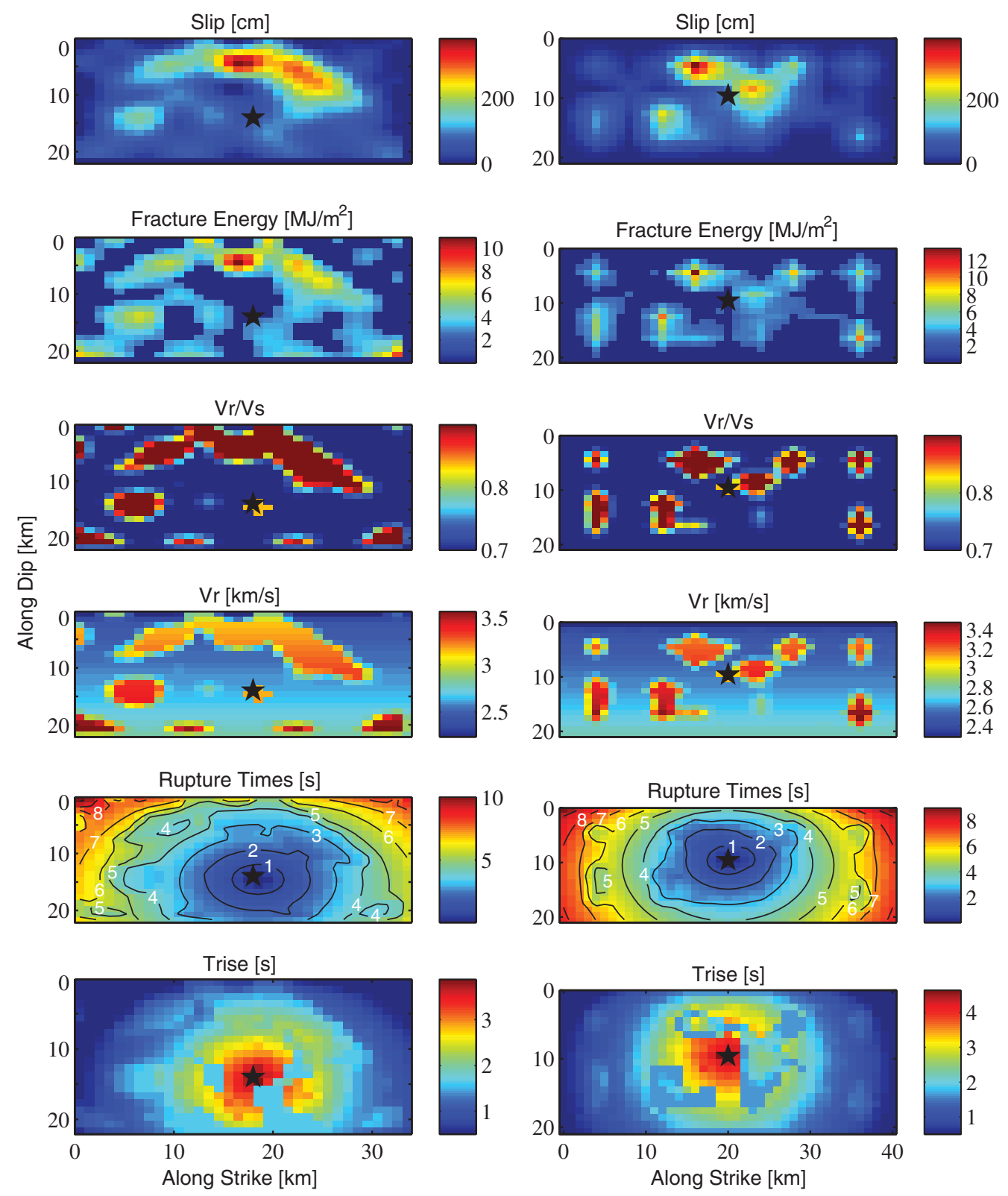

Figure 1. The PD source models using the G04 method for the 2000 Tottori earthquake based on the slip inversion of Iwata and Sekiguchi (2001) (left) and the slip inversion of Monelli et al. (2009) (right). From top to bottom, the inferred slip, the fracture energy, the ratio of the rupture speed and the shear-wave speed $\left(V_{r} / V_{S}\right)$, the rupture speed $\left(V_{r}\right)$, and the corresponding rupture times and the rise-time distributions are shown. 

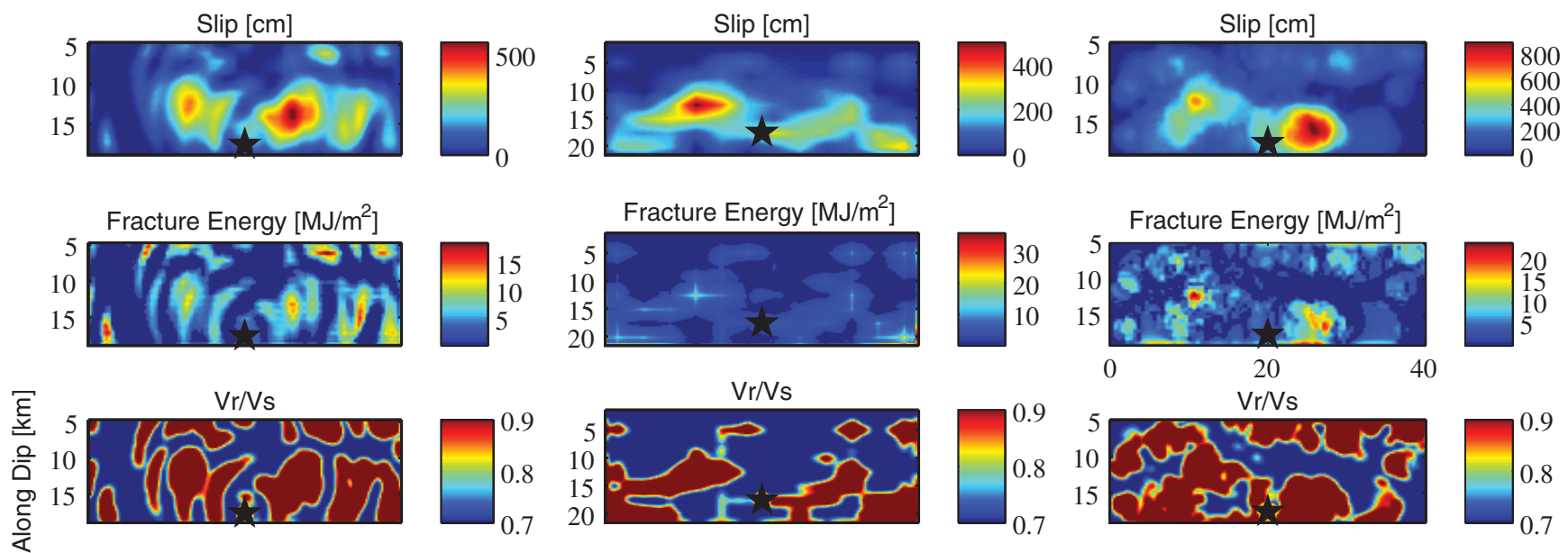

$\mathrm{Vr} / \mathrm{Vs}$
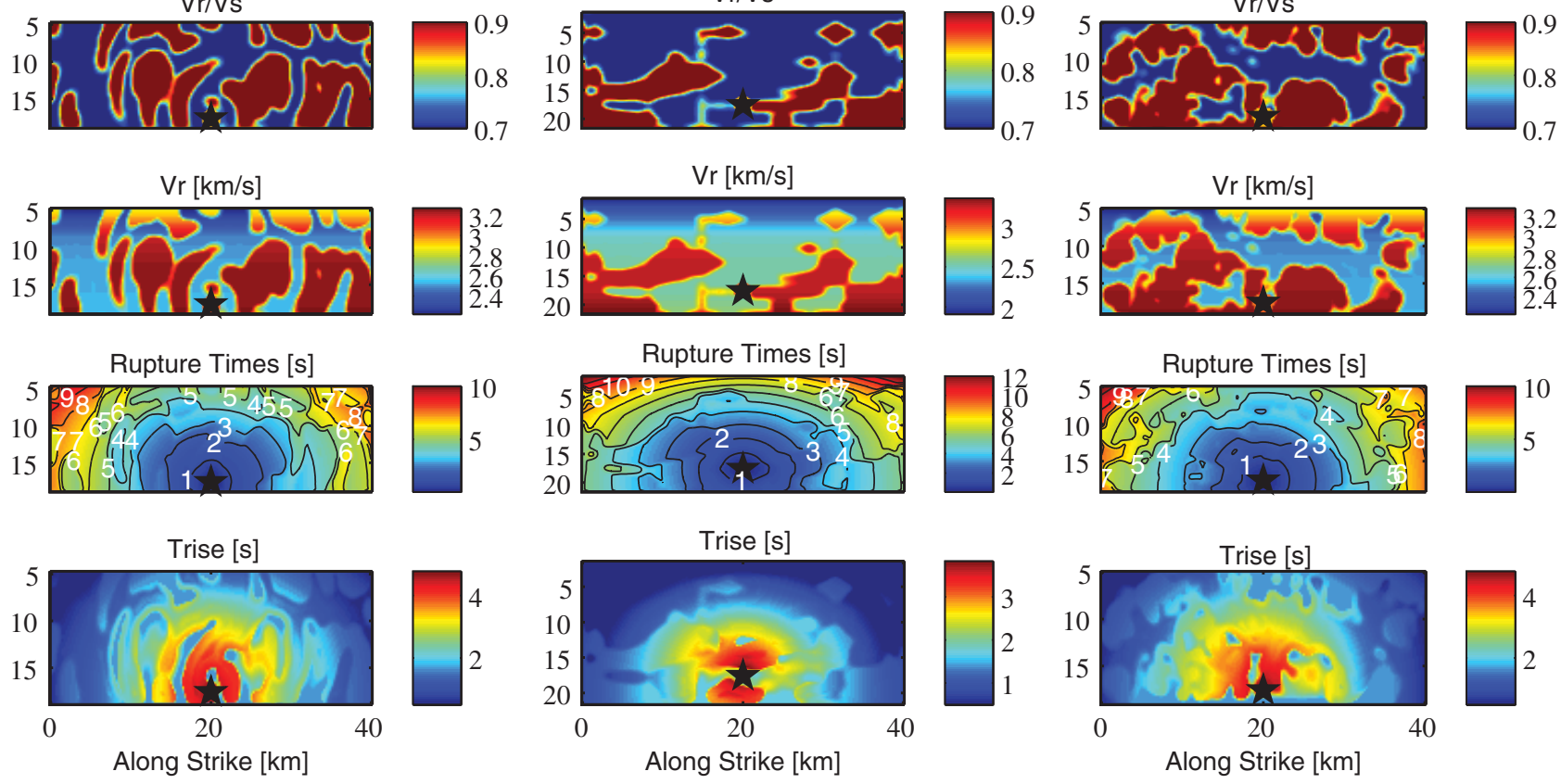

Figure 2. The PD source models using the G04 method for the 1989 Loma Prieta earthquake based on the slip inversion of Beroza (1991) (left), Wald et al. (1991) (middle), and Zeng and Anderson (2000) (right). From top to bottom, the slip, the fracture energy, the ratio of the rupture speed and the shear-wave speed $\left(V_{r} / V_{S}\right)$, the rupture speed $\left(V_{r}\right)$, and the corresponding rupture times and the rise-time distributions are shown.

Below the slip distributions we plot, from top to bottom, the PD source characterization: the fracture energy, $V_{r}$ (rupture speed) $/ V_{S}$ (shear wave speed), rupture time, and rise-time distributions computed in this study following G04 method.

As seen from the source models in Figure 1, the 2000 Tottori earthquake is a bilateral rupturing strike-slip event with $35 \sim 40 \mathrm{~km}$ rupture length but no surface rupture. The G04 PD method estimates relatively large rise times around the hypocenter, reaching about 3 4 s, before gradually decaying as the rupture evolves and reaches the fault boundaries. The PD rupture-velocity distribution changes only slightly, causing rather smooth rupture propagation. The 1989 Loma Prieta earthquake (Fig. 2), which is similar in size to the Tottori earthquake ( $\sim 0 \mathrm{~km}$ rupture length and $\sim 20 \mathrm{~km}$ rupture width), ruptured bilaterally with some dipping component. The rise times (bottom panel) estimated by the PD relations show similar distribution as in the Tottori earthquake with a maximum rise time of about $4 \mathrm{~s}$ around the hypocenter and then decreasing toward the fault boundaries. On the other hand, the Imperial Valley (Fig. 3) and the Izmit (Fig. 4) earthquakes ruptured unilaterally along $\sim 40 \mathrm{~km}$ and $\sim 100 \mathrm{~km}$ rupture lengths, respectively. While the rise times of the two bilateral ruptures reach to about $4 \mathrm{~s}$, the rise times of the unilateral rupturing Imperial Valley earthquake exceed $8 \mathrm{~s}$ (due to its overall longer rupture duration), although the size of this event is close to that of the Tottori and Loma Prieta earthquakes.

Figure 5a,b,c displays the station distributions, the fault traces, and the hypocenter locations for the Tottori, Loma Prieta, and Imperial Valley earthquakes, respectively. The stations represented by triangles are plotted on a grayscale reflecting the residual values computed by equation (1), at every station. The mean residual (mean [res]) is also computed for each PD model and depicted on each map in Figure 5.

To visualize the level of fit in our ground-motion simulations based on the PD source models, we plot the synthetics 

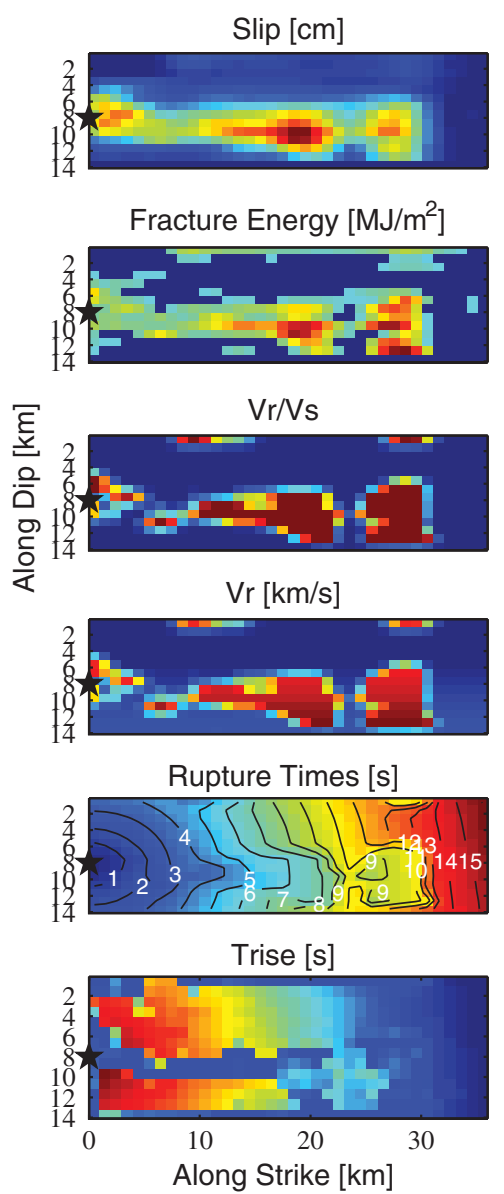
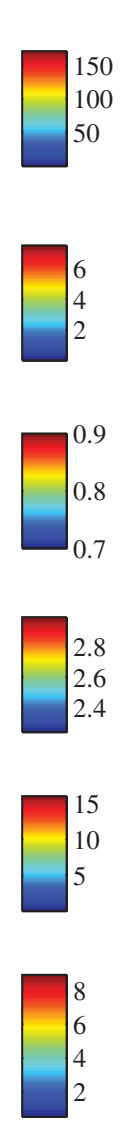

Along Strike $[\mathrm{km}]$

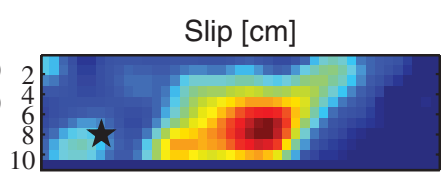

Fracture Energy $\left[\mathrm{MJ} / \mathrm{m}^{2}\right]$
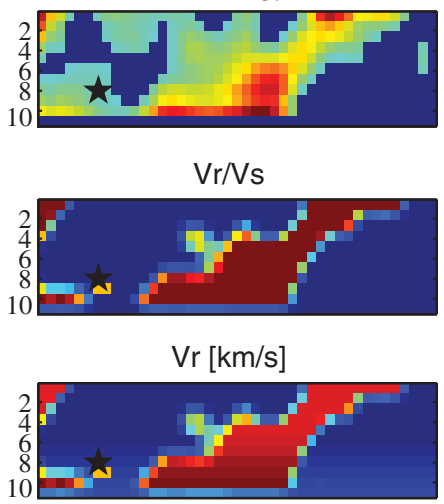

Rupture Times [s]
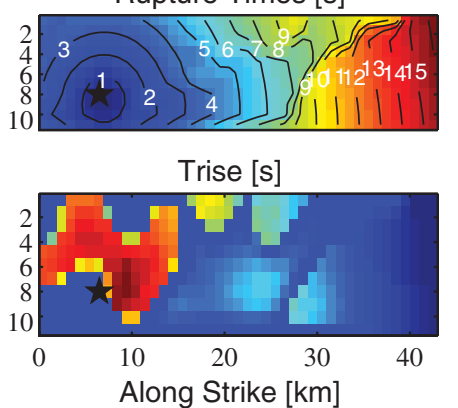
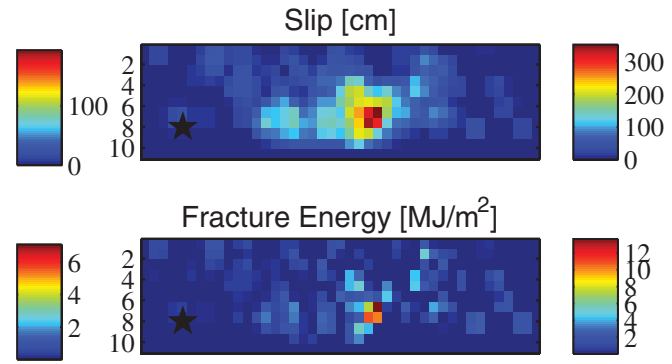

Fracture Energy $\left[\mathrm{MJ} / \mathrm{m}^{2}\right]$
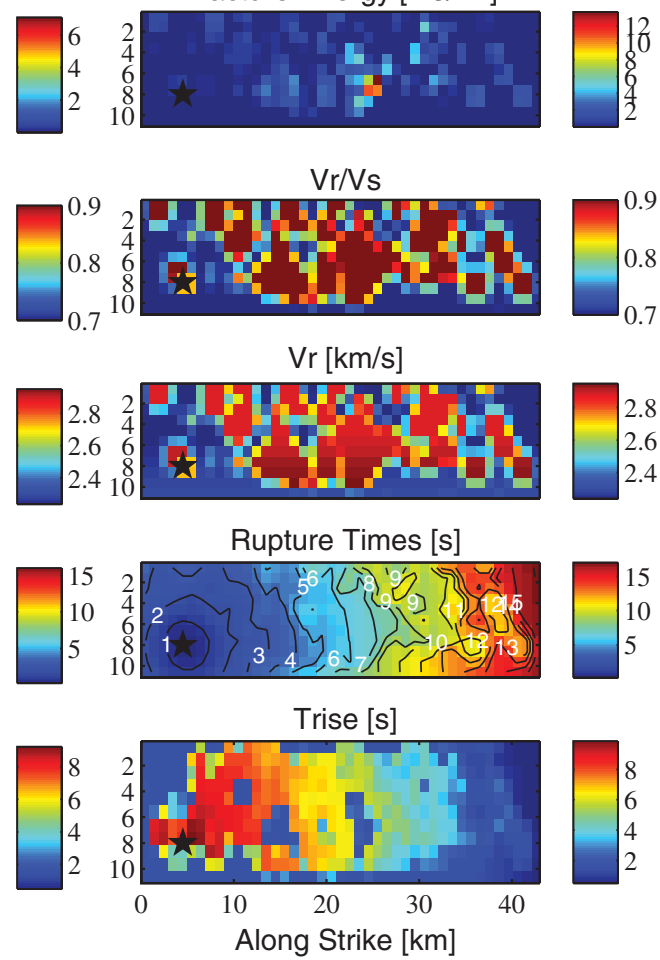
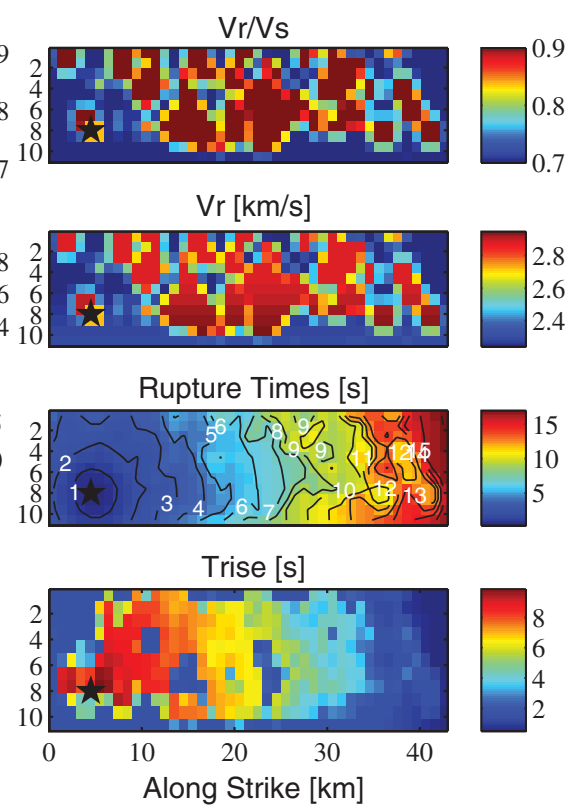

Figure 3. The PD source models using the G04 method for the 1979 Imperial Valley earthquake based on the slip inversion of Archuleta (1984) (left), Hartzell and Heaton (1983) (middle), and Zeng and Anderson (2000) (right). From top to bottom, the slip, the fracture energy, the ratio of the rupture speed and the shear-wave speed $\left(V_{r} / V_{S}\right)$, the rupture speed $\left(V_{r}\right)$, and the corresponding rupture times and the rise-time distributions are shown.

on top of recordings at several stations (see Appendix). Although the synthetic ground motions have slightly higher peak amplitudes in comparison with the recorded ground motions, the synthetics generally well reproduce the recordings in amplitude and waveform shapes. Similar results have been obtained for the 1989 Loma Prieta earthquake of $M_{\mathrm{w}} 6.9$ for which the synthetics also reasonably well fit the observations. For the Imperial Valley earthquake, although the size of the event is within the range of magnitudes of the G04 method, the synthetics are inadequate in comparison with the recorded ground motions. The amplitudes of the synthetic ground motions are mostly underpredicted, which may be due to the large rise times for this size of event reaching $8 \mathrm{~s}$ close to the hypocenter.

As stated previously, the parameterization of rise time is based on the total rupture duration aligned with the hypocenter in the along-strike direction. When the rupture propagation is unilateral, the rupture duration is apparently higher compared with the bilateral rupturing events of similar size. We believe that the rise-time parameterization is one of the main reasons of low-amplitude synthetics. These findings suggest that stopping phases or local healing fronts are needed to generate short rise times, where the local healing phases arrive earlier at the points around the hypocenter than a fault-boundary stopping phase. Our observations on synthetic ground motions associated with large rise times thus agree with studies of strong-motion data that consistently showed rise times significantly shorter than the overall rupture duration (Beroza and Mikumo, 1996). Heaton (1990), based on kinematic source inversion of past earthquakes, suggested that short time slip-velocity pulses dominate earthquakes in nature, and Beroza and Mikumo (1996) and Day et al. (1998) showed that the rise time is short over most of the fault, which is attributable entirely to the short scalelength slip/stress-drop heterogeneity required by the strongmotion data.

The effect of the rise-time parameterization for long ruptures with long rupture durations is even more pronounced in the 1999 Izmit earthquake, for which the maximum rise time reaches $12 \mathrm{~s}$ (Fig. 4). The relevant simulations results are displayed in the Appendix. The synthetic ground motions do not capture any of the characteristics of the recordings for 

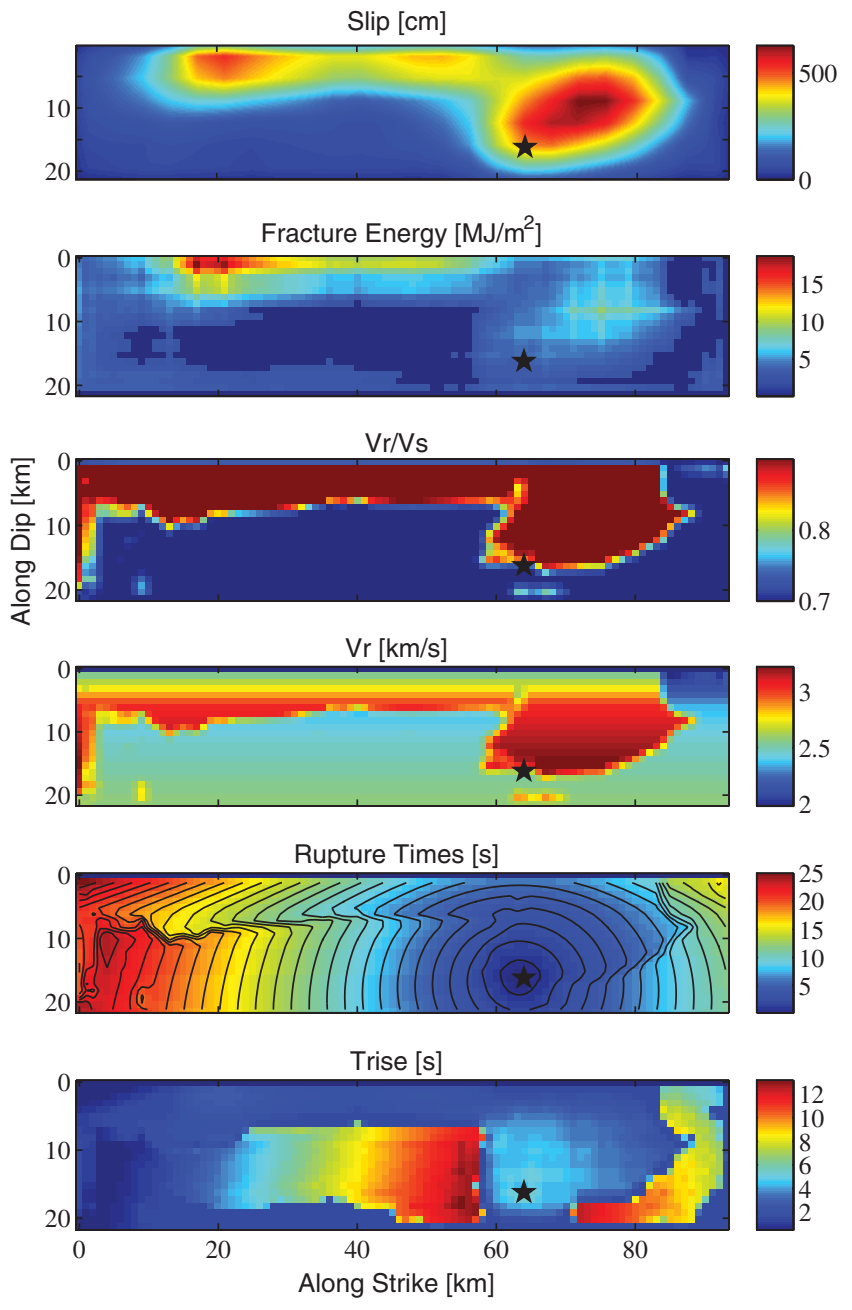

Figure 4. The PD source model using the G04 method for the 1999 Izmit earthquake based on the slip inversion of Yagi and Kikuchi (2000). From top to bottom, the slip, the fracture energy, the ratio of the rupture speed and the shear-wave speed $\left(V_{r} / V_{S}\right)$, the rupture speed $\left(V_{r}\right)$, and the corresponding rupture times and the rise-time distributions are shown.

this earthquake. In addition to the rise-time estimates, the large mismatch for these simulations may also be due to the very smooth rupture-speed distributions computed by the analytical formulation of Andrews (1976a). These results suggest that the G04 model does not provide a good estimate of the source parameters for this size of event.

\section{Toward New PD Relationships: Dynamic Rupture Simulations}

From the results presented previously, it becomes evident that new PD relationships that account for a broader range of physically plausible rupture speeds and effects of local stress heterogeneities (asperities) may improve ground-motion simulation, particularly for larger earthquakes. Guided by these considerations, we generate dynamic rupture models with stochastic initial stress distributions, covering a wider magnitude range ( $M$ 6-8), rupturing $10 \sim 100 \mathrm{~km}$ along strike. In addition to the new dynamic rupture simulations, we also utilized previously computed generic dynamic asperity models developed by Dalguer et al. (2008).

\section{Generic Dynamic Asperity Models}

Dalguer et al. (2008) developed generic models consisting of regularly spaced square asperities of high initial stress embedded in a surrounding background area of low initial stress. Using the slip-weakening friction model (Andrews, 1976b) and there simplified asperity models on the fault, these authors calibrated dynamic rupture models for buried and surface-rupturing earthquakes with stress-drop distributions that result in fault ruptures consistent with statistical observations of past events. Here, we deploy in total six asperity models from Dalguer et al. (2008), three of them being buried ruptures (at $3 \mathrm{~km}$ depth) with $12.5 \mathrm{~km}$ and $25 \mathrm{~km}$ fault lengths, with either a single or multiple asperities. Three of the larger models are surface-breaking events with 50, 75, and $100 \mathrm{~km}$ rupture length along strike, having 2, 3, and 4 asperities, respectively.

\section{Stochastic Dynamic Rupture Models}

In addition to the generic asperity models, we carry out dynamic rupture simulations with stochastic initial stress distributions. The dynamic rupture simulations are carried out with the 4th order staggered-grid 3D-FD code of Olsen et al. (2006, 2008, and 2009), which solves the velocity-stress wave equation explicitly. The code uses the highly accurate staggered-grid split node (SGSN) fault representation method for dynamic rupture simulations developed by Dalguer and Day (2007).

We apply the linear slip-weakening friction model (Andrews, 1976). The friction coefficients $\left(\mu_{s}, \mu_{d}\right.$, static and dynamic friction coefficient, respectively), the normal stress $\left(\sigma_{N}\right)$, and the slip-weakening distance $\left(D_{c}\right)$ are taken constant across the fault. For all models in our dynamic dataset, we set the $D_{c}=0.2 \mathrm{~m}, \mu_{d}=0.58$, and $\sigma_{N}=120 \mathrm{MPa}$. We changed $\mu_{s}$ between 0.6 and 0.8 , where larger values of $\mu_{s}$ are assigned to longer surface-rupturing events, thus generating a larger magnitude earthquake. The chosen friction coefficients are generic values consistent with laboratory experiments (Byerlee, 1978). Notice that thermal weakening (e.g., Beeler et al., 2008), such as flash heating that results in dramatic reduction of friction coefficients, are not considered in our study. Based on this parameterization, the yield stress $\left(\tau_{y}\right)$, the frictional sliding stress $\left(\tau_{d}\right)$, and therefore the fracture energy $\left(G_{c}\right)$ are also constant along the fault. We generate stochastic initial stresses $\left(\tau_{o}\right)$ using a spatial random field model (Mai and Beroza, 2002; Ripperger et al., 2007) with a von Karman autocorrelation function and uniform distribution of stress values (see Fig. 6). The random stress field depends on three parameters: the correlation length along strike (acx), along dip (acz), and the Hurst exponent $(H)$ that controls the spectral decay. The selection criteria for the 

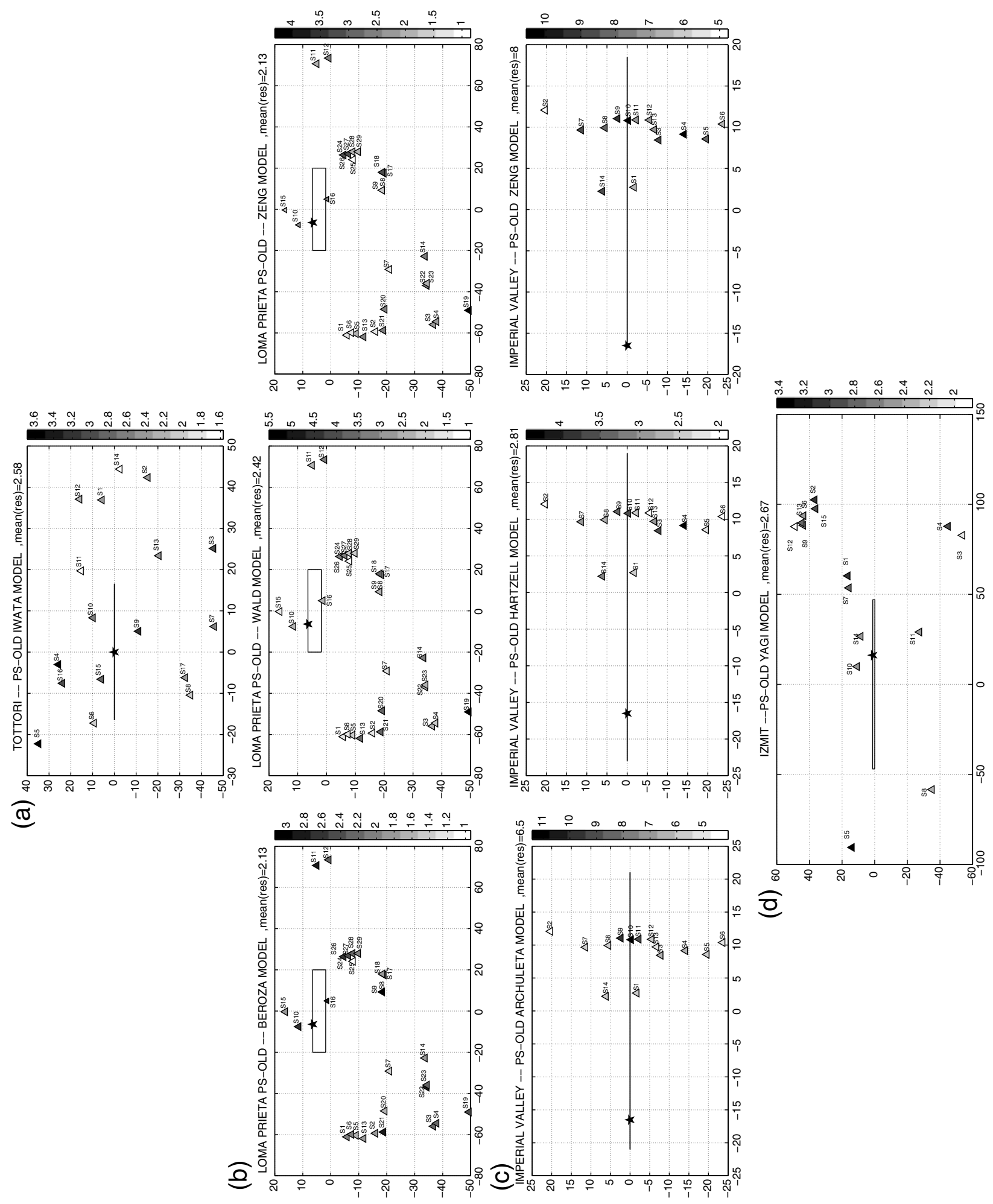

密

递

ีํㅇ ?

$\overrightarrow{2}$

$\stackrel{0}{\circ}$

ê

i $\frac{0}{n}$

을

ฮ

흥

8.

is:

త్

홍

ఏ

일

종

홍

迥

흘 즐

言莺

크

‡

荬

동

를

홍

롤

巳

क्षे.

. ज

छू.

.

흘

$\because$

.을

के

这市

은.

ن

产全 
(a)

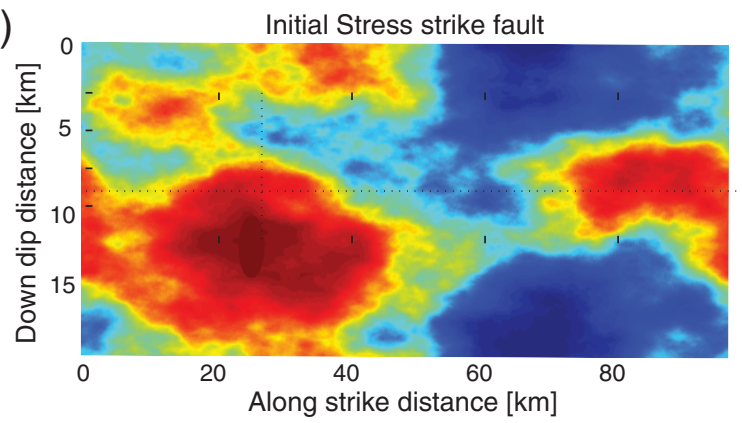

(c)

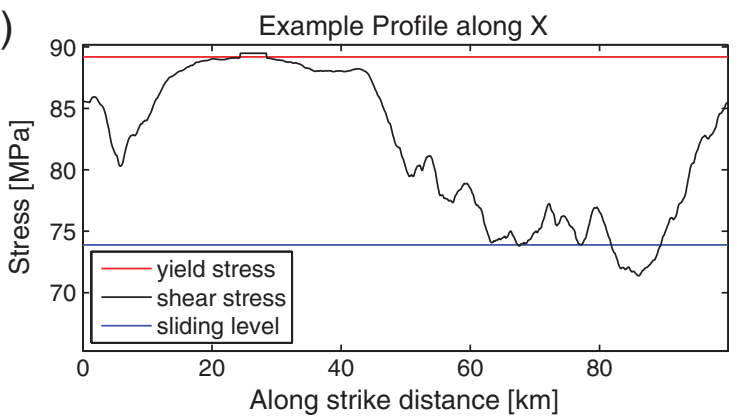

(b)
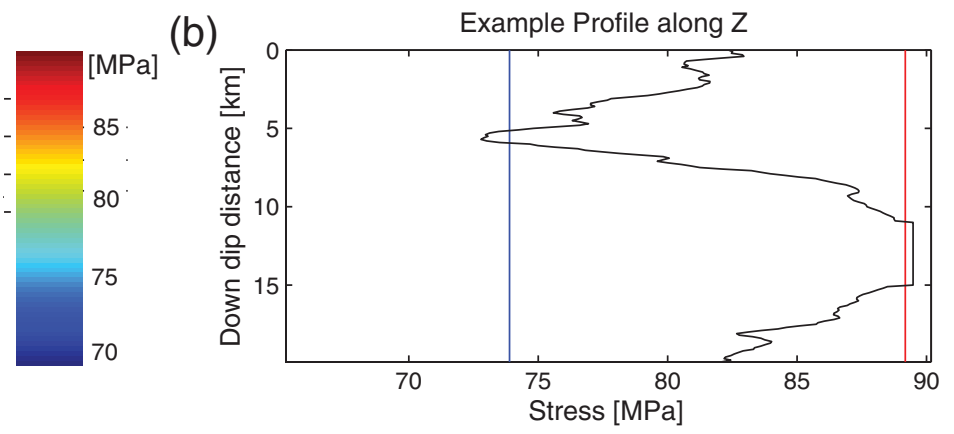

(d)

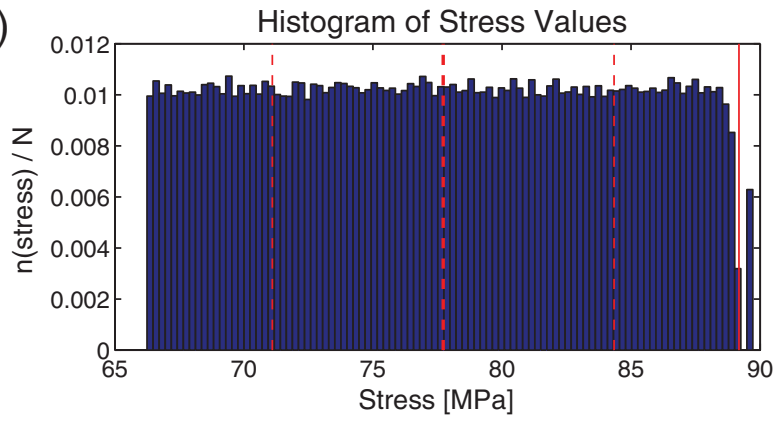

Figure 6. (a) Stochastic initial stress distribution over a 100-km fault length. (b) Stress profile along dip. (c) Stress profile along strike. (d) Probability density function of the initial stress distribution.

correlation lengths and the Hurst exponent are based on Mai and Beroza (2002) in which correlation length scales with source dimension. The work of Mai and Beroza (2002) shows that slip models with multiple small asperities are characterized by short correlation lengths, while slip models with only one or two large slip patches have longer correlation lengths. The asperity size increases with source dimension (or magnitude) and tends to have longer correlation lengths. We followed the simple regression relations provided by Mai and Beroza (2002) that relate rupture length to acx, and rupture width to acz. We then slightly changed acx around the value found from the scaling relations to create variable stress distributions with single and multiple asperities. Because there is no evidence that the Hurst exponent $(H)$ depends on magnitude (Mai and Beroza, 2002), we assume $0.5 \leq H \leq 1$ in our models, given by Mai and Beroza (2002) as the range, which provides the best fit to the observed spectral decays.

We develop a set of models with fault lengths $L=10$ to $100 \mathrm{~km}$, and fault widths $(W)$ limited to maximum fault width of $20 \mathrm{~km}$, representing the brittle crust of the earth. Like the Dalguer et al. (2008) models, our stochastic initial stress dynamic models with fault lengths less than $50 \mathrm{~km}$ remain buried ruptures whose top-edge stops at $3 \mathrm{~km}$ beneath the Earth's surface. The longer events $(L>50 \mathrm{~km})$ are modeled as surface-rupturing earthquakes. We group the events due to their predefined fault lengths and perform 4-5 dynamic rupture simulations in each group, varying correlation lengths and the Hurst exponent $(H=0.5 \sim 1)$ in each group. We assume that the variation of average stress-drop changes with the $L / W$ ratio, based on the observations in Dalguer et al. (2008). In total we conduct 35 stochastic initial stress dynamic rupture simulations, in addition to the 6 generic asperity models adopted from Dalguer et al. (2008). Figure 6 shows an example plot of a stochastic initial stress distribution over a $100-\mathrm{km}$ fault length together with a profile of stresses along strike and along dip, as well as the probability density function of the initial stress values. Having set the yield and frictional sliding stresses constant and generating a heterogeneous initial stress distribution, we are explicitly varying the strength excess $\left(S_{e}=\tau_{y}-\tau_{o}\right)$ and the stressdrop $\left(\Delta \sigma=\tau_{o}-\tau_{d}\right)$ distributions.

All of the dynamic rupture models are representations of vertical strike-slip earthquakes, with magnitudes ranging between $M_{\mathrm{w}} 6$ and 8 . Table 1 summarizes the dynamic simulations over different rupture lengths.

\section{New PD Relations Derived from Dynamic Rupture Simulations}

Using the suite of 41 dynamic rupture models described previously, we now examine the relations between dynamic source parameters (e.g., stress parameters) and kinematic source parameters (e.g., rupture velocity, rise time) with the aim to derive a new PD characterization that allows for surface-breaking and buried ruptures over a larger magnitude range and includes supershear rupture speed.

\section{Rupture Velocity $\left(V_{r}\right)$}

The essential step toward modeling the temporal slip evolution is to determine a distribution of rupture velocity. G04 uses the analytical relationship of Andrews (1976) between rupture velocity, fracture energy, stress drop, and crack 
Table 1

Model Parameters Used for the Dynamic Rupture Simulations of the Generic Asperity Models in Dalguer et al. (2008)

\begin{tabular}{lcccccccc}
\hline & \multicolumn{3}{c}{ Four Buried Models } & \multicolumn{5}{c}{ Surface-Rupturing Faults } \\
\hline$L(\mathrm{~km})$ & 12.5 & 17.5 & 25 & 35 & 50 & 65 & 75 & 100 \\
$W(\mathrm{~km})$ & 17.5 & 17.5 & 17.5 & 17.5 & 20 & 20 & 20 & 20 \\
Number of scenarios & 5 & 4 & 6 & 4 & 4 & 4 & 4 & 4 \\
& & & & & & & &
\end{tabular}

length, valid in simple antiplane strain, with uniform stress drop and frictional properties. The relationship of Andrews (1976) models subshear rupture velocity and does not allow the rupture to increase to supershear speed at any point along the fault plane. While this approach is consistent with the majority of instrumentally recorded earthquakes, for which average rupture velocity remains subshear, it ignores reported observations of supershear rupture (Archuleta, 1984; Spudich and Cranswick, 1984; Olsen et al., 1997; Ellsworth and Celebi, 1999; Bouchon et al., 2000; Bouchon and Vallée, 2003).

Our set of dynamic models allows us to study the variability of rupture velocity and the existence of supershear rupture. We calculate the rupture velocity at every point across the fault plane, following the procedure of Pulido and Dalguer (2009). The dynamic rupture simulations provide the position of the rupture front at each time step, at each point on the fault plane. We then calculate the rupture slowness vectors, defined as the gradient of rupture times following

(a) 1000

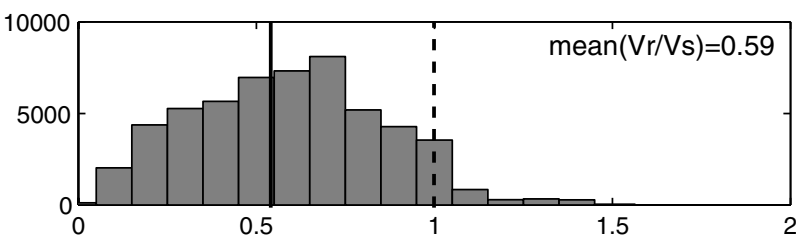

(c)

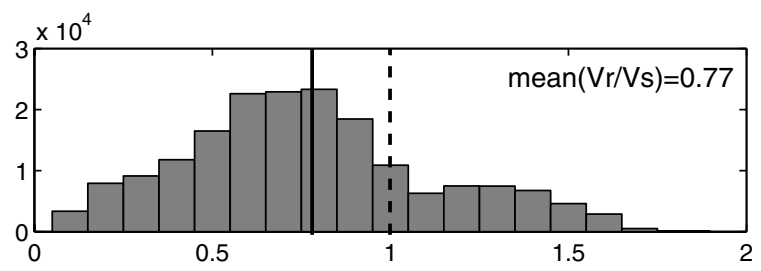

(e)

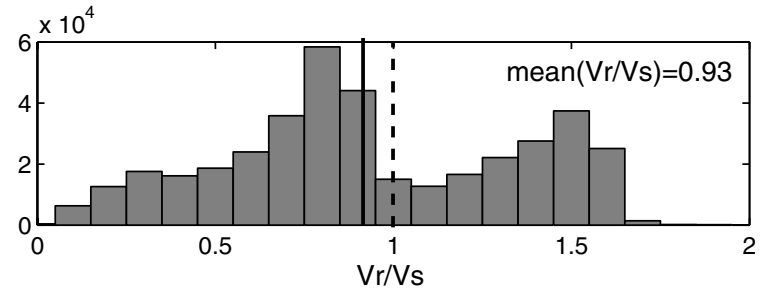

equation 2 in Pulido and Dalguer (2009). Finally, the rupture velocity at each point is computed based on the rupture slowness vector (equation 3 in Pulido and Dalguer, 2009). We then compute histograms of the $V_{r}$ distribution of each dynamic simulation. Because these $V_{r}$ distributions are similar for all events of similar fault length, we group the dynamic rupture models according to their effective rupture lengths $\left(L_{\text {eff }}\right)$, and categorize the dataset into three groups of buried events ( $L_{\text {eff }}<35$, denoted as B1, B2, B3), and three groups of surface-rupturing events $\left(35 \leq L_{\text {eff }} \leq 100, \mathrm{~S} 1, \mathrm{~S} 2, \mathrm{~S} 3\right)$. $L_{\text {eff }}$ is computed considering areas of the fault that slipped more than $1 \mathrm{~cm}$. Calculating $L_{\text {eff }}$ rather than using the predefined fault length will avoid incorrect interpretation due to parts of the fault that did not rupture. Groups B1, B2, and B3 correspond to the buried events with $L_{\text {eff }} \leq 12.5 \mathrm{~km}$, $12.5<L_{\text {eff }} \leq 25 \mathrm{~km}$, and $25<L_{\text {eff }} \leq 35 \mathrm{~km}$, respectively. Groups S1, S2, and S3 correspond to the surface-rupturing events with $35<L_{\text {eff }} \leq 50 \mathrm{~km}, 50<L_{\text {eff }} \leq 75 \mathrm{~km}$, and $75<L_{\text {eff }} \leq 100 \mathrm{~km}$, respectively.

(b)

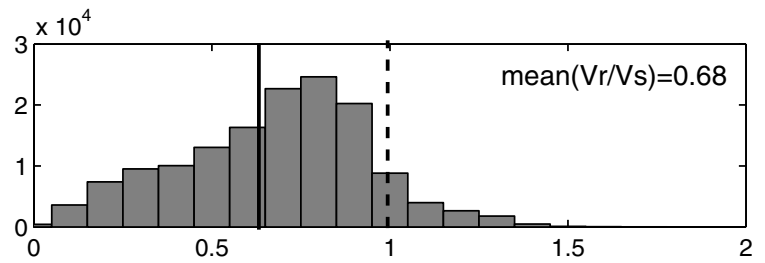

(d)

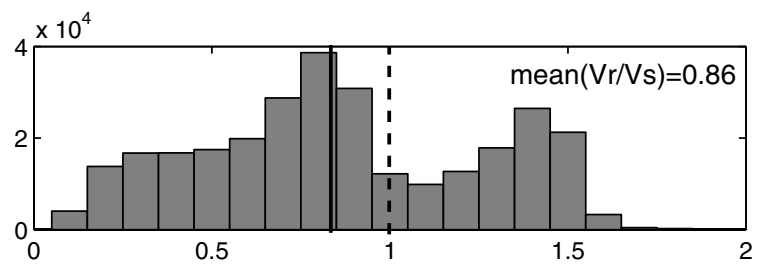

(f)

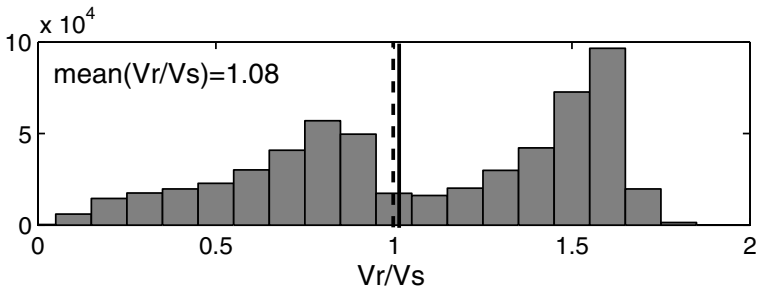

Figure 7. Distribution of the ratio between rupture speed and shear-wave speed $\left(V_{r} / V_{S}\right)$, plotted as a histogram for each group of earthquakes determined by their effective rupture length, $L_{\text {eff }}$. (a) Group B1, buried earthquakes with $L_{\text {eff }} \leq 12.5 \mathrm{~km}$; (b) group B2, buried earthquakes with $12.5<L_{\text {eff }} \leq 25 \mathrm{~km}$; (c) group B3, buried earthquakes with $25<L_{\text {eff }} \leq 35 \mathrm{~km}$; (d) group S1, surface-rupturing earthquakes with $35<L_{\text {eff }} \leq 50 \mathrm{~km}$; (e) group S2, surface-rupturing earthquakes with $50<L_{\text {eff }} \leq 75 \mathrm{~km}$; and (f) group S3, surface-rupturing earthquakes with $75<L_{\text {eff }} \leq 100 \mathrm{~km}$. 
Figure 7 shows the $V_{r} / V_{S}$ distributions $\left(V_{r} / V_{S}\right.$ value on each subfault over the fault plane for all models) as histograms for each group of earthquakes determined by their $L_{\text {eff }}$. The vertical axes of the histograms in Figure 7 show the number of points (subfaults) in that group of events that experience the velocity ratios on the horizontal axis. Each entry shows the local value on the subfault. These histograms show that local supershear rupture velocities exist for events of all sizes, although the average rupture velocity of most of the events remains subshear (except for Group S3 that has mean $V_{r} / V_{S}$ slightly above 1 ). Physics-based numerical experiments (Andrews, 1976b) show that for an in-plane (mode II) crack, rupture initially propagates with a low speed and then accelerates toward the Rayleigh wave speed. During this process, a peak shear stress associated with the $S$ wave traveling ahead of the rupture may exceed the yield stress, triggering a secondary rupture. This secondary crack eventually becomes unstable, and the leading crack-tip of the rupture then becomes supershear. In addition, when rupture propagates along heterogeneous stress fields, stress waves ahead of the rupture front encounter patches of prestress close to the yielding criteria. If these waves have sufficient amplitude, they can nucleate secondary ruptures with short duration that may trigger supershear propagation. Our dynamic simulations reveal the previously identified physical processes of supershear rupture speed over small, localized regions on the fault.

Another significant observation based on the $V_{r} / V_{S}$ distributions in Figure 7 is that only very few points on the fault actually rupture with exactly the shear-wave speed. The rupture either propagates subshear or supershear, but does not propagate between Rayleigh and shear-wave speeds. Similar results were reported by Ely et al. (2010) for long faults (large $L / W$ aspect ratio). The findings of our numerical simulations agree with analytical results of steady-state propagation in an in-plane semi-infinite crack (e.g., Burridge et al., 1979), showing that rupture speeds between the Rayleigh and $S$-wave velocity is forbidden. In this wave-speed domain, the energy flux into the rupture front becomes negative, suggesting that rupture speed in this zone is not sustainable. The rupture propagation with $S$-wave speed $\left(V_{r}=V_{S}\right)$ shown in Figure 7 is mainly attributed to the propagation along the antiplane direction (along the width of the fault at the hypocenter area), where $S$ wave rupture speed is physically plausible. The fact that local supershear rupture speed areas increase with earthquake size for strike-slip faults (as seen in Fig. 7) suggests that earthquakes on long faults (large $L / W$ aspect ratio) predominantly rupture in mode II, in which supershear rupture speed is more likely to occur.

Our stochastic simulations, supported by theoretical and observed supershear ruptures, suggest that locally supershear rupture velocity may occur on faults with heterogeneous stress. Because faults in nature are known to generate heterogeneous in slip distribution, as seen from kinematic source inversions (e.g., the finite-source rupture model database; see
Data and Resources); consequently, in stress distribution, we conjecture that local supershear rupture may prevail in nature.

Based on the previous arguments, we seek a new parameterization of rupture speed, which can replace the analytical equation used in the G04 method and allow local supershear rupture velocities. High rupture speeds are concentrated within the asperity areas, while the transition to supershear rupture speeds occurs in areas of high stress drop. Based on the analysis of our dynamic simulations, we propose a simple linear relation between rupture speed, stress drop, and strength excess, which is formulated in equation (2) as

$$
V_{r} / V_{S}=\beta_{0}(\mathrm{Sd} / \mathrm{Sd}+\mathrm{Se})+\beta_{1} \pm \sigma \text { for } V_{r} \leq V_{P},
$$

where $V_{P}$ is the $P$-wave velocity, $\beta_{0}$ and $\beta_{1}$ are the slope and the intercept of the linear relation, respectively, that are determined through a least-squares regression, $\mathrm{Sd}$ is the stress drop, Se is the strength excess, and $\sigma$ is the standard deviation. Because we construct our dynamic models with constant yield and frictional sliding stresses and only vary the initial stress distribution, stress drop and strength excess are linearly related as a result of the initial conditions in our dynamic modeling in equation (3):

$$
\mathrm{Se}=15.28-1.0 \mathrm{Sd} \text {. }
$$

Figure 8 shows the ratio of rupture speed and shearwave speed $\left(V_{r} / V_{S}\right)$ as a function of stress drop and the strength excess for all points on the fault, for one dynamic simulation from each group (i.e., dynamic models with rupture lengths of $12.5 \mathrm{~km}, 25 \mathrm{~km}, 35 \mathrm{~km}, 50 \mathrm{~km}, 75 \mathrm{~km}$, and $100 \mathrm{~km}$, respectively). As seen in Figure 8, for events of increasing rupture lengths, different coefficients $\beta_{0}$ and $\beta_{1}$ are required for rupture models of different rupture lengths:

$$
\begin{aligned}
& \beta_{0}=0.19, \quad \beta_{1}=0.5 \quad \text { for } L_{\mathrm{eff}} \leq 12.5, \\
& \beta_{0}=0.49, \quad \beta_{1}=0.5 \quad \text { for } 12.5<L_{\mathrm{eff}} \leq 25, \\
& \beta_{0}=0.72, \quad \beta_{1}=0.5 \quad \text { for } 25<L_{\mathrm{eff}} \leq 35, \\
& \beta_{0}=0.75, \quad \beta_{1}=0.6 \quad \text { for } 35<L_{\mathrm{eff}} \leq 50, \\
& \beta_{0}=0.81, \quad \beta_{1}=0.7 \quad \text { for } 50<L_{\mathrm{eff}} \leq 75,
\end{aligned}
$$

and

$$
\beta_{0}=0.92, \quad \beta_{1}=0.8 \text { for } 75<L_{\text {eff }} \leq 100 .
$$


Equations (4a) through (4f) represent a set of earthquake realizations, as listed in Table 1 . These results imply that the ratio $V_{r} / V_{S}$ exhibits a distinct scaling behavior, that is, earthquakes with longer fault length tend to have larger $V_{r} / V_{S}$. The standard deviation of these equations fluctuates between 0.3 and 0.4 , and the correlation coefficient varies between 0.6 and 0.7 (note that single-event correlation coefficients are $\sim 0.8$, i.e., higher than the one for groups of events with similar rupture lengths). Equations (2)-(4) can then be applied to calculate a distribution of rupture speed for a PD approximation. Notice in Figure 8 that $V_{r}$ approaches naturally the
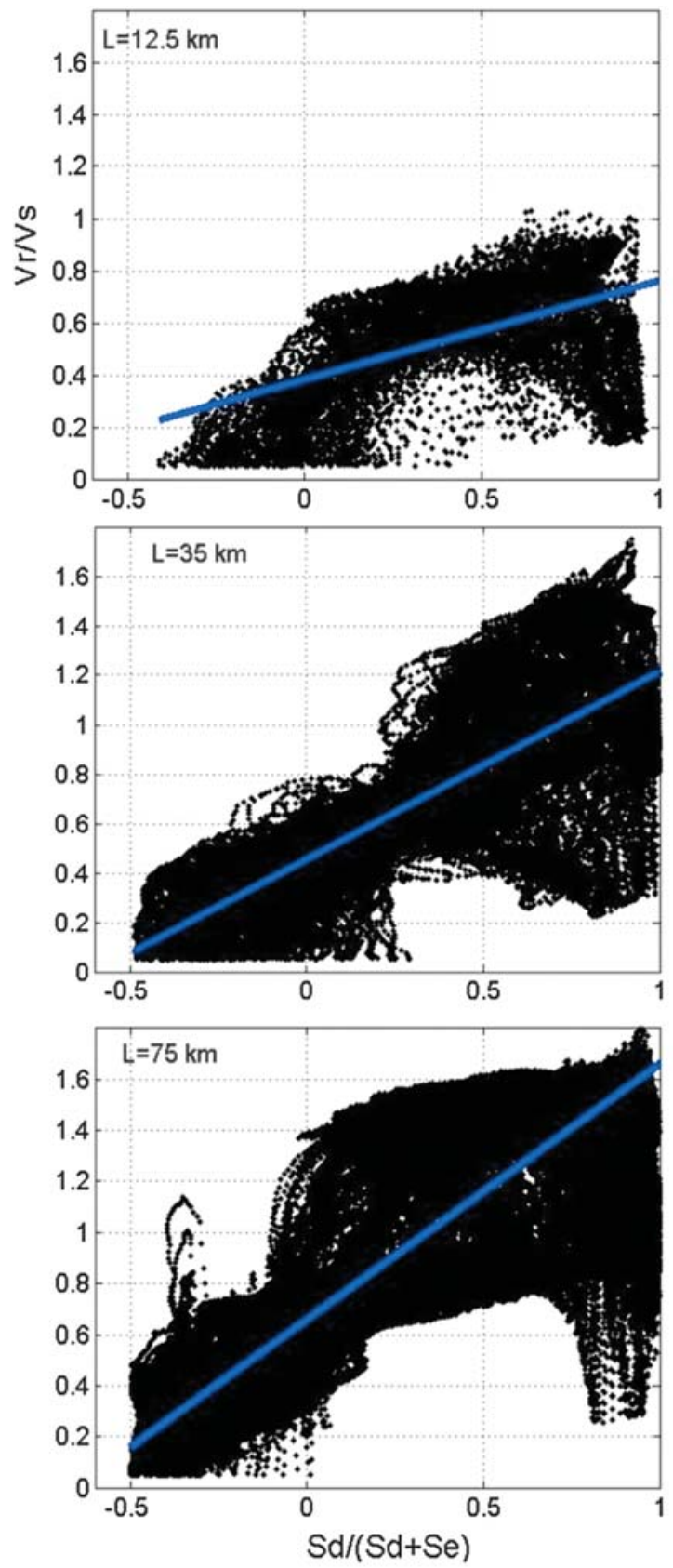

limit of a physically plausible rupture velocity, that is, the $P$-wave velocity, at patches in which Se is very small. Therefore, when applying these equations for rupture-speed calculations, the condition $V_{r} \& l t ;=V_{P}$, (as stated in equation 2), has to be enforced.

\section{Slip-Velocity Function}

The parameterization of the slip-velocity function is of critical importance for kinematic ground-motion simulations. Dynamically derived slip-rate functions are complex
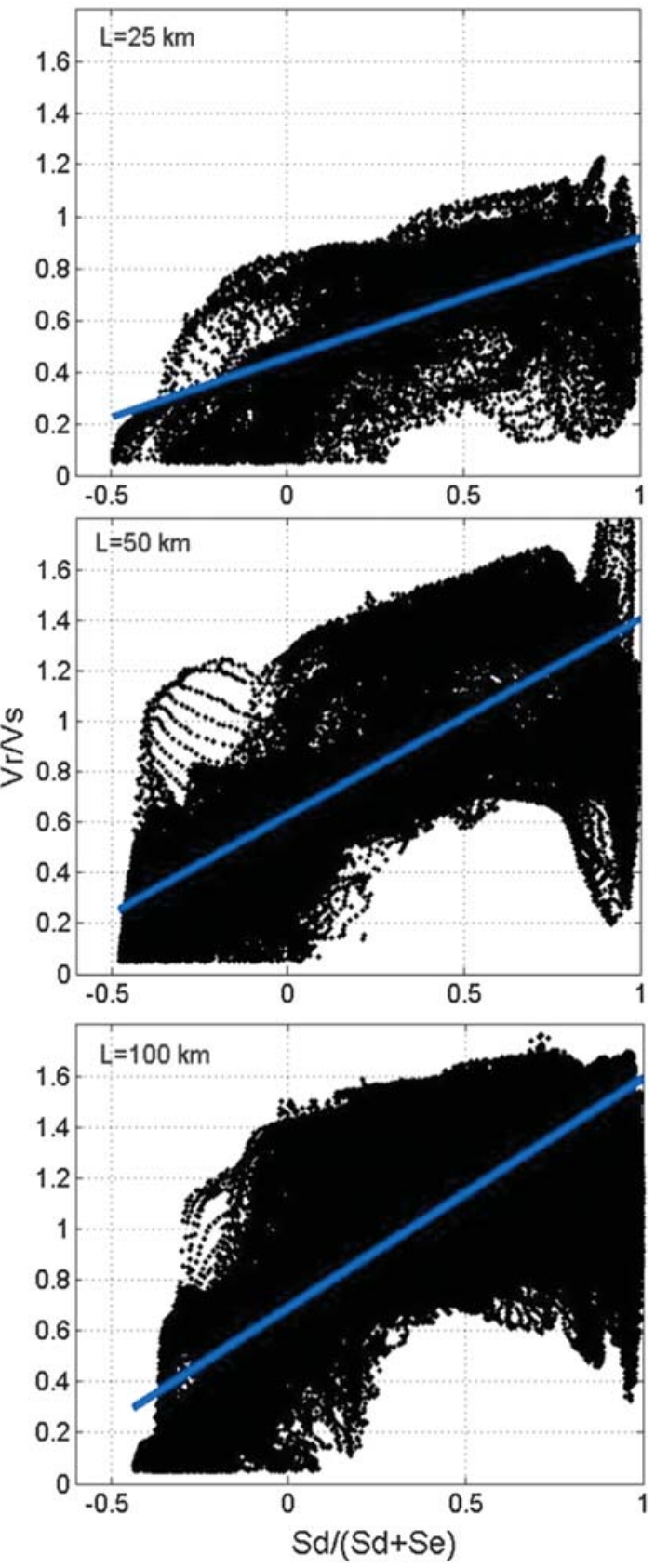

Figure 8. Ratio of rupture speed to shear-wave speed $\left(V_{r} / V_{S}\right)$ as a function of stress drop and strength access [Sd $\left./(\mathrm{Sd}+\mathrm{Se})\right]$, plotted for all points over the fault plane for one dynamic simulation from each group; from left to right and top to bottom, dynamic models with rupture lengths $12.5 \mathrm{~km}, 25 \mathrm{~km}, 35 \mathrm{~km}, 50 \mathrm{~km}, 75 \mathrm{~km}$, and $100 \mathrm{~km}$ are shown. 
in shape, and therefore difficult to parameterize. Canonical slip-rate functions (boxcar, triangular, or trapezoidal functions) can be applied for simplicity, but source-time functions (STF) compatible with rupture dynamics are generally preferable. There have been efforts to produce simplified yet physically realistic STFs that are relatively easy to parameterize, while still being consistent with rupture dynamics. Figure 9a, b show dynamically derived slip and slip-rate functions. Figure 9a is a slip-rate function in the asperity zone, which is described by the maximum slip $\left(D_{\max }\right)$ and defined as the areas where $\left[66 \% D_{\max } \leq D\right]$ (Mai et al., 2005). Figure 9b is located in the surrounding low-slip background area. As a result of an extensive analysis of our dynamic simulations, we found that dynamically derived slip-rate functions within the asperities (Fig. 9a) show similarities with the Yoffe function, proposed by Tinti et al. (2005) as dynamically consistent kinematic slip-rate function (Fig. 9c). The Yoffe function captures the relevant characteristics of the dynamic SVF and therefore can be utilized in PD ground-motion simulations; it is fully parameterized by three parameters: $V_{\text {peak }}$, the maximum slip-rate; $T_{\mathrm{acc}}$, the acceleration time; and $\tau_{r}$, the total rise time. We extract these parameters from our dynamic simulations to develop scaling relations for their prediction. We replace the two-triangle parameterization of slip-rate function used in G04 with the Yoffe function in the new PD method. Because the slip-rate functions in the low slip areas $\left(D<0.66 D_{\max }\right)$ are not well resolved and their effect on ground motions are likely to be rather small, we exclude the rise times in the low slip areas for the rise-time parameterization in this paper. We will use a constant rise time for the background areas in the ground-motion simulations.

\section{Acceleration Time, $T_{\text {acc }}$}

We derive the $T_{\text {acc }}$ from our dynamic models. The mean value of $T_{\text {acc }}$ as well as its distribution along the fault is mainly controlled by the slip-weakening distance, $D_{c}$. However, the detailed scaling of $T_{\text {acc }}$ is poorly constrained; in addition we do not compute $D_{c}$ in the PD approach. Hence, in the later ground-motion simulations with Yoffe function parameterization, we use constant $T_{\text {acc }}$, as suggested by Tinti et al. (2005), who fix $T_{\text {acc }}$ at value between 0.1 and $0.3 \mathrm{~s}$. Because this parameter is not well constrained, we tested different values of $T_{\text {acc }}$ between 0.1 and $0.3 \mathrm{~s}$, which produce insignificant changes in the low-frequency ground-motion synthetics. All simulations in this study with the new PD approach therefore use a constant $T_{\text {acc }}$ of $0.2 \mathrm{~s}$.

\section{Total Rise Time, $\tau_{r}$}

We define the rise time as the time from $5 \%$ to $95 \%$ of the total slip, as in G04. For the characterization of the risetime distribution, we first plot the rise-time values $\tau_{r}$ as a function of rupture times (Fig. 10b), corresponding to the asperities in the slip model shown in Figure 10a. The rise times surrounded by each asperity are plotted with different colors. The black points are associated with the first asperity (a)
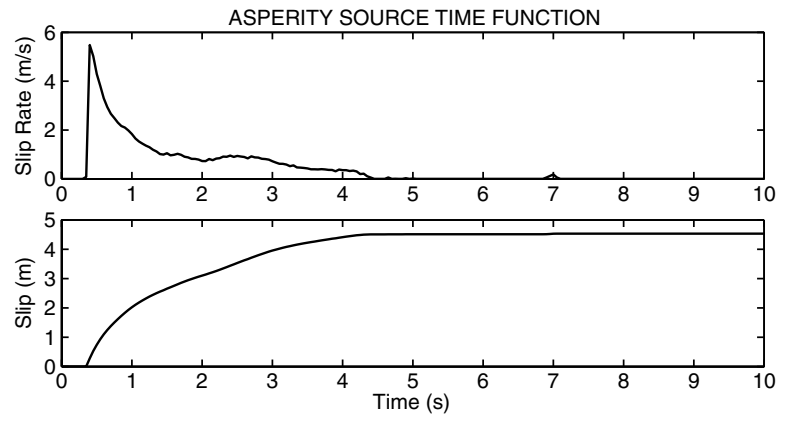

(b)
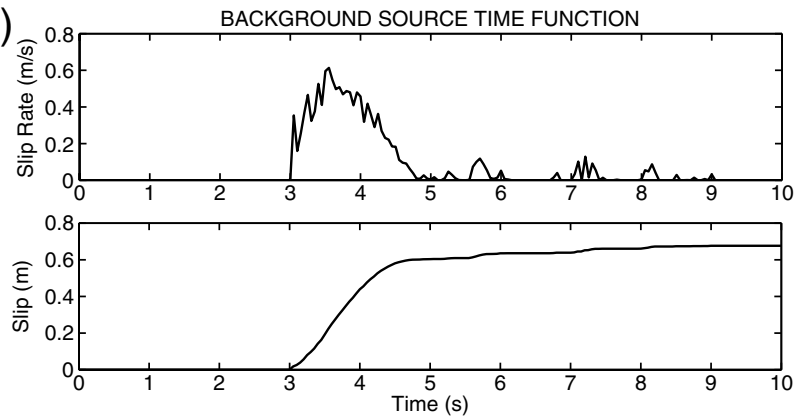

(c)

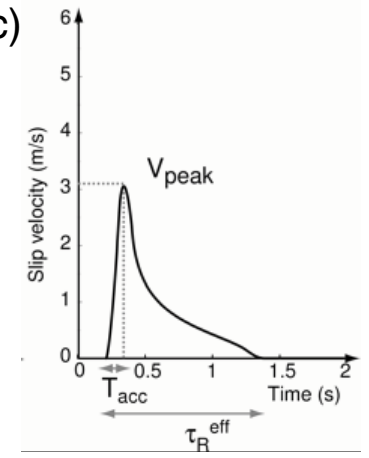

Figure 9. (a) and (b) show dynamically derived slip and sliprate functions from the model shown in Figure 10. (a) Slip-rate function in the asperity zone described by the maximum slip $\left(D_{\max }\right)$ and defined as the areas where $\left[66 \% D_{\max } \leq D\right]$ (Mai et al., 2005). (b) Slip-rate function located in the surrounding low-slip background area. (c) Illustration of the Yoffe function proposed by Tinti et al. (2005).

(surrounding the hypocenter), the blue points are the risetime values within the second asperity, and the red points show the rise times of points surrounded by the third, farthest asperity from the hypocenter. Despite the general trend that the linear rate of increase of rise-times diminishes as the rupture times increase, there is no unique rise-time behavior along surface-breaking faults with multiple asperities. However, there is a repetitive behavior of rise times for separate asperity patches, which seems to be similar for buried multiple asperity models. Figure 10a,b shows that the surrounding asperities control the rise times, rather than the total fault duration. This implies that the stopping phases from the asperity boundaries limit the rise times before the backpropagating pulses from the fault boundaries reach these points. These results are consistent with our initial validation 


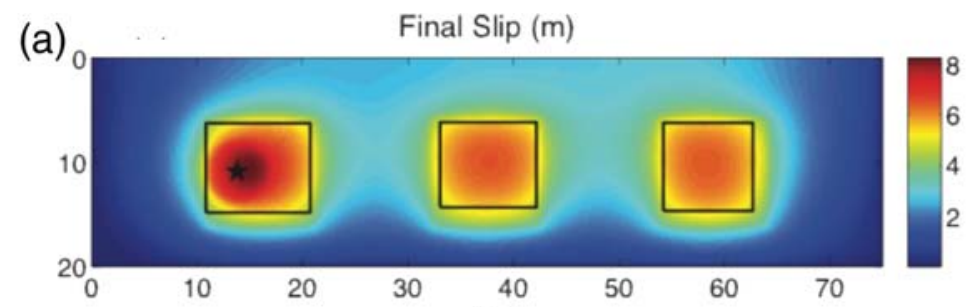

(b)

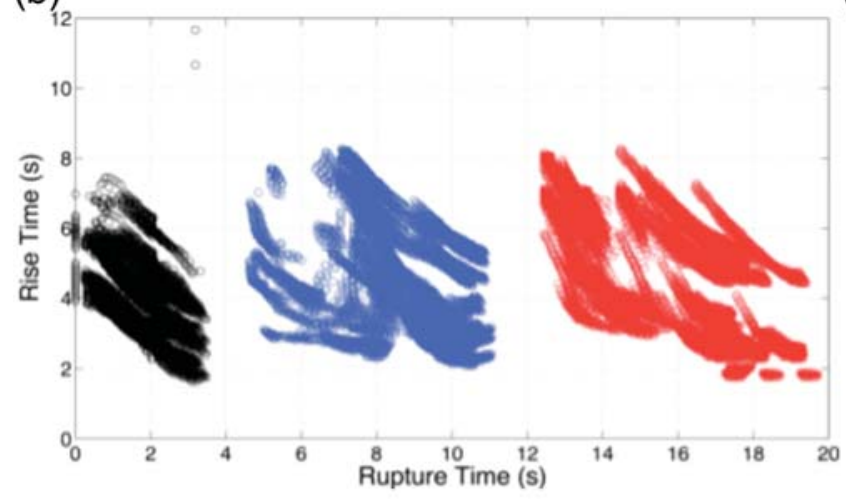

(d)

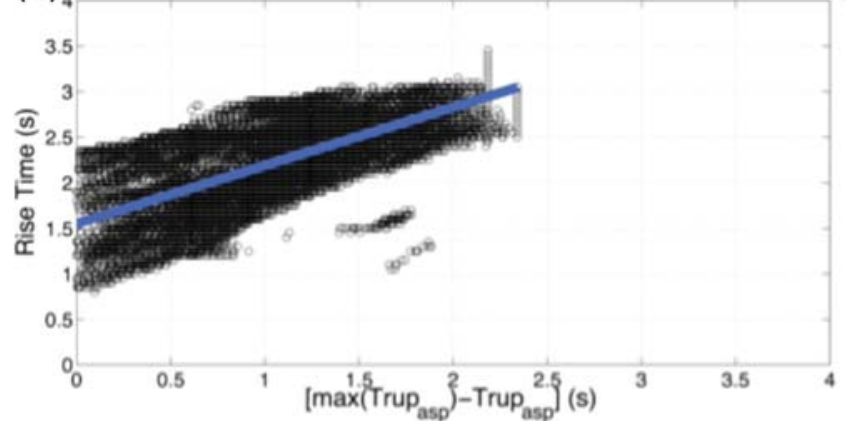

(c)

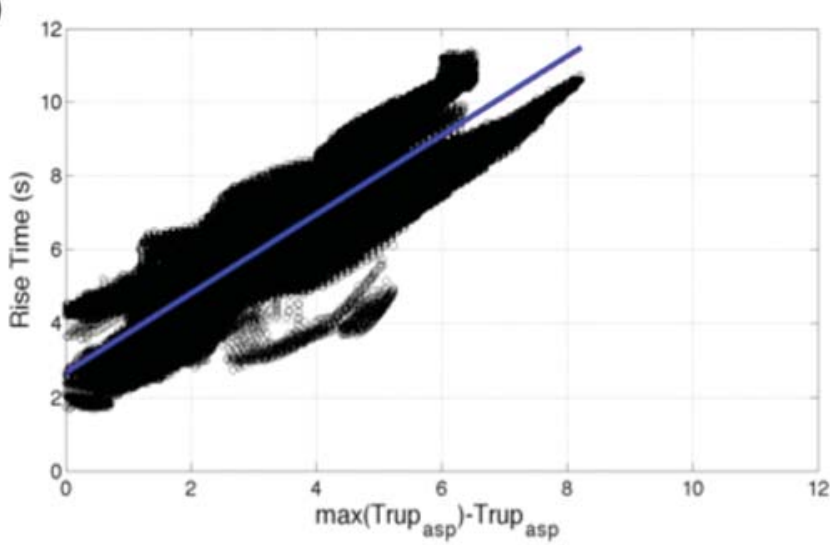

(e)

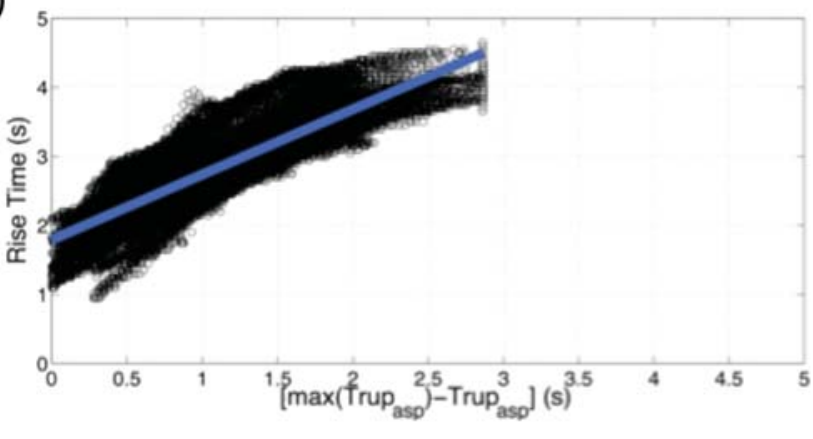

Figure 10. (a) Slip distribution of a generic asperity dynamic model taken from Dalguer et al. (2008). The asperities are surrounded by black dashed rectangles, and the hypocenter is shown by the black star. (b) Rise-time values $\tau_{r}$ plotted as functions of rupture times. The rise times surrounded by each asperity in (a) are plotted with different colors. The black points are associated with the first asperity surrounding the hypocenter, the blue points are the rise-time values within the second asperity, and the red points show the rise times of points surrounded by the third asperity (farthest asperity from the hypocenter). (c) The rise-time values plotted as a function of the difference between the asperity-rupture-duration and the corresponding rupture times for points within all three asperities. (d,e) The relation between the total rupture duration of the asperity versus the rise times within the asperity for a buried and a surface-rupturing earthquake generated by stochastic initial stress distributions, respectively.

tests using the G04 method that also indicate overpredicted rise times based on the total rupture duration.

Figure 10c shows the rise-time values plotted as a function of the difference between the asperity-rupture-duration and the corresponding rupture times for points within all three asperities. As seen from Figure 10c, considering the total rupture duration of each asperity for the computation of the rise times of that asperity presents a single relationship, and it will avoid the unrealistically high rise-time predictions for long ruptures as experienced in the application of the G04 method to $40 \mathrm{~km}$ long unilateral Imperial Valley and the $100 \mathrm{~km}$ unilateral Izmit earthquake simulations.

For our stochastic initial stress dynamic simulations, similar distributions of rise times are found over the asperities. Figure 10d,e illustrates the relation between the total rupture duration of the asperity versus the rise times within the asperity for a buried and a surface-rupturing earthquake. As a result of exploring 35 stochastic initial stress dynamic models and the 6 generic asperity models, we conduct a linear regression analysis using the new parameterization:

$$
\tau_{r}=\alpha\left(\tau_{\text {asp }}-t_{\text {rupt }}\right)+\beta \pm \sigma,
$$

in which $\tau_{r}$ is the rise time, $\tau_{\text {asp }}$ is the total asperity duration, $t_{\text {rupt }}$ is the rupture time, $\alpha$ and $\beta$ are the slope and the intercept of the linear relation, and $\sigma$ is the standard deviation. Applying a least-squares approach, we find two sets of coefficients: one for buried earthquakes $\left(L_{\text {eff }} \leq\right.$ $50 \mathrm{~km})$ and another for surface-breaking earthquakes $\left(L_{\text {eff }}>50 \mathrm{~km}\right)$ : 


$$
\alpha=0.6, \quad \beta=1.5 \text { for } L_{\text {eff }} \leq 50,
$$

and

$$
\alpha=0.9, \quad \beta=1.7 \quad \text { for } L_{\text {eff }}>50 .
$$

The critical rupture length where the rise-time relations differ is where the standard scaling relations may break down at $L_{\text {eff }}>2.5 W$ (Hanks and Bakun, 2003). Once the rupture width approaches the thickness of the seismogenic zone, the rupture length becomes about twice the rupture width, and ruptures grow predominantly in the along-strike direction.

\section{Ground-Motion Simulation Using the New PD Relations}

The main purpose of this study is to develop physicsbased kinematic source models to replace the traditional pure kinematic approaches in ground-motion simulation tools. Because we obtain new empirical relations for characterizing the spatiotemporal evolution of slip velocity, rise time, and rupture velocity based on principles from rupture dynamics, we can apply the proposed relations to generate PD source models for ground-motion prediction. We first compute the stressdrop distributions from the published slip models of the 2000 Tottori, 1979 Imperial Valley, and 1999 Izmit earthquakes, using the same slip models as in our G04 validation. We then calculate the kinematic source parameters (i.e., $\tau_{r}, T_{\text {acc }}, V_{r}$ ) using the new PD relations. In the ground-motion simulations, we apply the Yoffe function (Tinti et al., 2005) as a dynamically consistent kinematic slip-rate function, in agreement with our spontaneous dynamic rupture simulations. Because our PD method only models the rise times within asperity areas, we adopt constant rise times in the background areas. The constant values are chosen according to the seismic moment of the target earthquake and corresponding scaling relation (Somerville et al., 1999). For completeness, we also perform several tests by changing the constant background rise-time values within the range $\pm 1 \mathrm{~s}$. The changes in the synthetics are insignificant. This implies that the contribution of the low slip areas of the fault plane to the ground motions is negligible, in agreement with the study of the strong-motion generation area of Miyake et al. (2003).

Figure 11 shows the two PD source models using the slip inversions of Iwata and Sekiguchi (2001) and Monelli et al. (2009) for the Tottori earthquake. The PD characterization using our new relations for the 1979 Imperial Valley earthquake is illustrated in Figure 12 for the three slip inversions: Archuleta (1984), Hartzell and Heaton (1983), and Zeng and Anderson (2000). The updated PD source characterization for the 1999 Izmit earthquake is depicted in Figure 13.

Figure 14a,b,c shows the station distributions, with a grayscale reflecting the residual values at each site, the simplified fault trace, and the hypocenter locations for the Tottori, Imperial Valley, and Izmit earthquakes, respectively. Although the G04 method performs fairly well for the moderate size bilateral Tottori earthquake (Fig 5), some improvements in misfit are achieved in terms of the decreased mean residual values for both PD models. The improvements in the new synthetic ground-motion waveforms are recognizable, in comparison with the synthetics using the G04 source characterization. The enhancement in ground-motion simulation using the proposed PD approach, compared with the G04 method, is even more pronounced in the 1979 Imperial Valley earthquake. Also for the Izmit earthquake, the mean residuals are significantly decreased using our new PD approach, in comparison with the performance of the G04 method. The new synthetics capture the detailed features of the recorded ground motions. Table 2 compares the mean residuals for the Tottori, Imperial Valley, and Izmit earthquake ground-motion simulations using the G04 and the new PD characterization. As seen from the table, the mean residuals for all the models are significantly reduced using the new PD source characterization for ground-motion simulation.

While our proposed PD approach successfully characterizes the source complexities and performs well in ground-motion simulations for moderate-to-large size earthquakes, PD models using certain slip inversions perform better than others for the same earthquake. For instance, for the Imperial Valley earthquake simulation tests, the PD model based on the slip inversion of Hartzell and Heaton (1983) performs best, with minimum mean residuals compared with the other two slip inversion results. Thus, using several slip inversion results to characterize the PD source parameters, each giving a different level of fit between simulations and recordings, may provide information on which slip inversion may be most consistent with physical constraints. Because our PD approach is constrained with physics-based dynamic rupture simulations, the models producing better waveform fits are most likely physically more plausible.

\section{Discussion}

The feasibility to parameterize kinematic models to best emulate dynamically consistent rupture behavior, and reduce, for example, the artificial variance in ground-motion estimates, is a difficult target. Rupture speed, the form of the slip-velocity function, and adequate parameterization of this function are essential ingredients for realistic source characterization. The best attempt to parameterize the kinematic models is the so-called PD approach that constrains kinematic source parameters with results obtained from forward dynamic simulations. It is important to note, however, that dynamic models highly depend on the assumed friction constitutive law, and thus constrained kinematic models area affected by the assumed friction model. It needs to be emphasized that limited knowledge of the dynamic constitutive behavior of faults at seismogenic depths for real earthquakes renders well-defined physical assumptions for friction at seismogenic depths not unique. Different classes of slip weakening and rate-and-state friction models, or combinations of them, are physically plausible. The assumptions regarding the friction model are reflected in the slip-velocity function (e.g., Rojas et al., 2009). This raises the question 

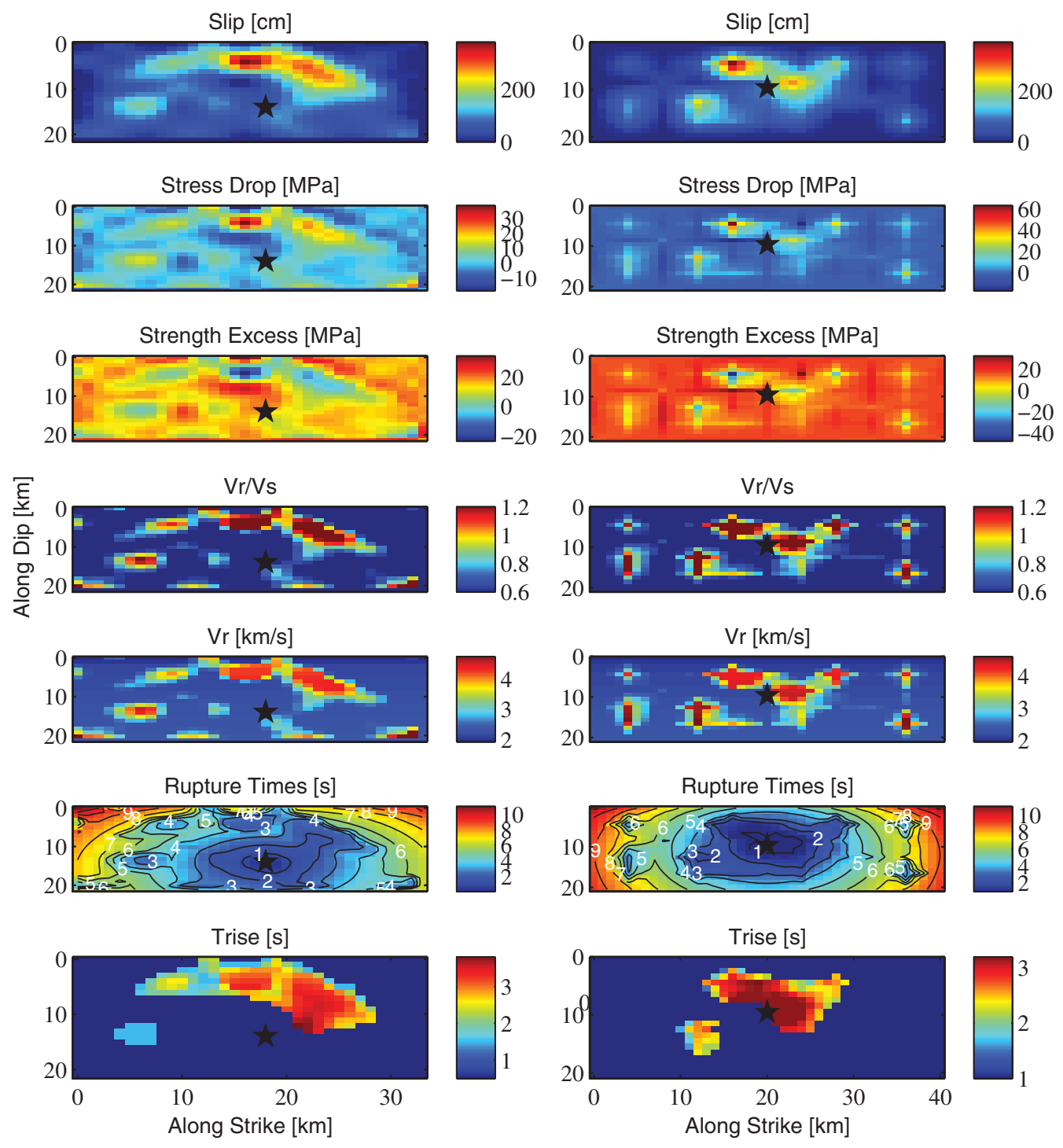

Figure 11. The new PD source models for the 2000 Tottori earthquake based on the slip inversion of Iwata and Sekiguchi (2001) (left column), and based on the slip inversion of Monelli et al. (2009) (right column). From top to bottom, the slip, stress drop, strength excess, the ratio of the rupture speed and the shear wave speed $\left(V_{r} / V_{S}\right)$, the rupture speed $\left(V_{r}\right)$, the corresponding rupture times and the rise time distributions are shown.

how the corresponding slip-velocity function can be represented in the physics-based kinematic model. Few attempts have been made to address these questions. For example, the slip-velocity function of Hisada (2000) emulates a Kostrovlike function (an analytical solution of the forward dynamic problem; Kostrov, 1966) by multiple triangular basis functions, while the Yoffe function proposed by Tinti et al. (2005) is dynamically consistent within the framework of linear slip-weakening friction models. Other slip-velocity functions that result from other mechanisms of friction, such as healing and thermal weakening process (e.g., Rice et al., 2005), are not yet well studied for the application in physicsbased kinematic models. Only through a combination of insights from dynamic models with different friction mechanisms, simulation of ground-motion observations from many individual earthquakes, and through experimental and theo- retical studies of friction, we will be able to address the question stated previously and to reduce the nonuniqueness of the physical assumptions.

In the line of the previous discussion, we utilize the welldefined linear slip-weakening friction model to propose a new PD relationship, following the approach proposed by G04, but adopting the Yoffe function for the slip-velocity parameterization. Our contribution in the proposed PD model is notable when simulating real earthquakes and comparing the results with the G04 method. The following comparisons are highlighted and discussed:

1. As seen from the simulations of past earthquakes using the G04 method and the new proposed PD approach (Figs. 1 and 11 for the Tottori earthquake, Figs. 3 and 12 for the Imperial Valley earthquake, and Figs. 4 and 13 for the 

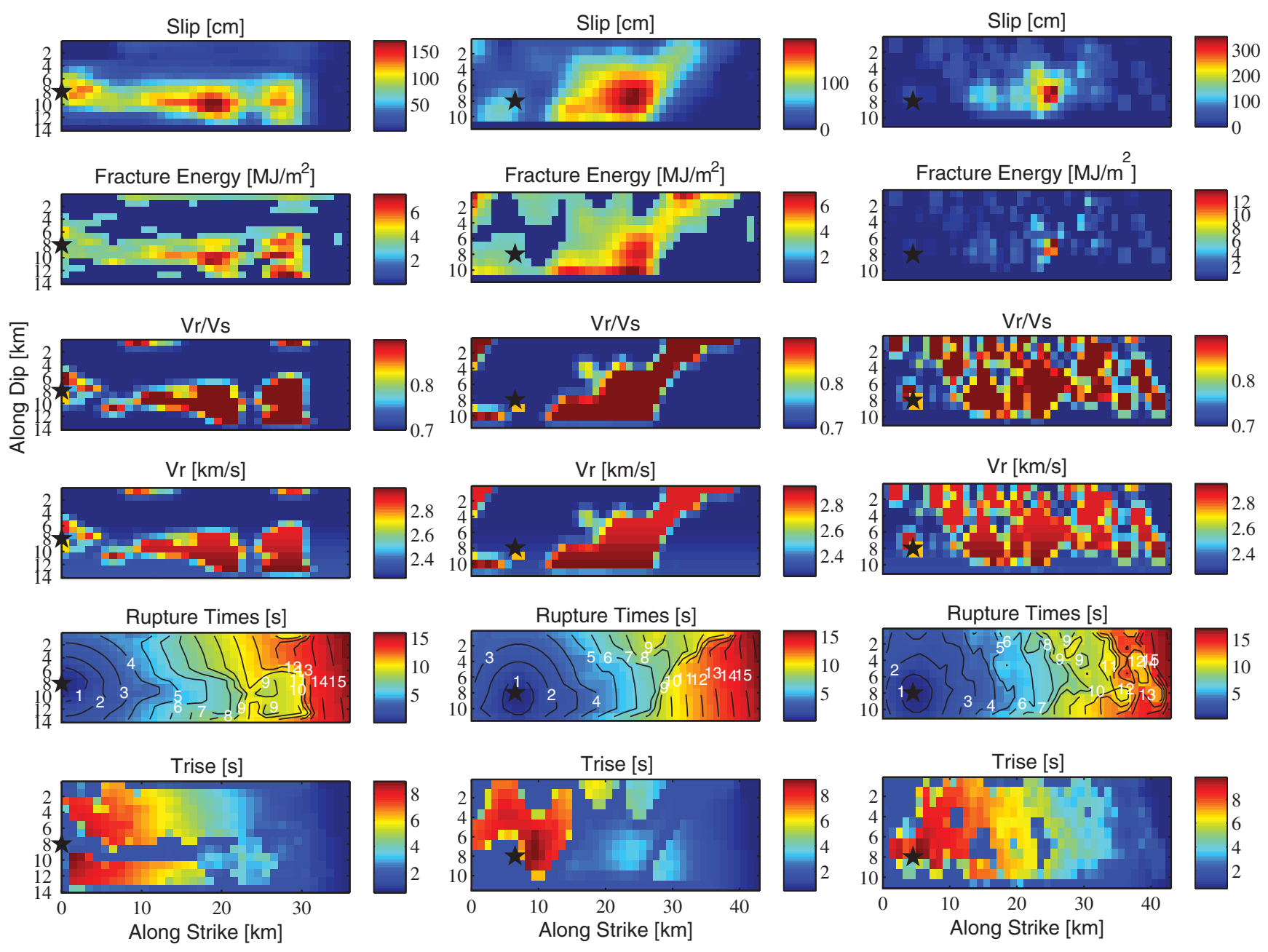

Figure 12. The new PD source models for the 1979 Imperial Valley earthquake based on the slip inversion of Archuleta (1984) (left), Hartzell and Heaton (1983) (middle), and Zeng and Anderson (2000) (right). From top to bottom, the slip, the fracture energy, the ratio of the rupture speed and the shear wave speed $\left(V_{r} / V_{S}\right)$, the rupture speed $\left(V_{r}\right)$, and the corresponding rupture times and the rise-time distributions are shown.

Izmit earthquake), the difference in the rise-time distribution, both in terms of the values and spatial distributions along the fault plane, is significant. In our proposed PD approach, the rise-time distribution is associated with the high slip/stress-drop areas, and the rise-time values are significantly shorter.

2. The rupture speed does not reflect strong differences between the two models, in terms of spatial distributions, but the local rupture-velocity values are considerably different. This difference arises from the parameterization assumptions used in each model. While the G04 method computes rupture-speed distribution based on theoretical assumptions that depend on the fracture energy and the stress distributions, resulting in subshear rupture speed only, in the new PD methodology the rupture speed is a consequence of the stress heterogeneity characterized directly from dynamic rupture computation that allows supershear speeds. In the latter, high rupture speeds are associated with high stress drop and low strength excess areas. The major difference can be seen in Figures 4 and 13 for the Izmit earthquake source models. The maximum rupture speed in Figure 4 is about $3 \mathrm{~km} / \mathrm{s}$, while the maximum rupture speed value for the new PD approach reaches $5 \mathrm{~km} / \mathrm{s}$ at localized points in the high slip/ stress-drop asperities. In our proposed PD model, parts of the fault east from the hypocenter rupture with supershear rupture speed over $20 \mathrm{~km}$ length, while the background areas rupture with subshear values $(\sim 3 \mathrm{~km} / \mathrm{s})$. This modeling result is comparable with the previous observational studies that report supershear rupture speed for the Izmit earthquake (Ellsworth and Celebi, 1999; Bouchon et al., 2000) based on the anomalously short $S-P$ time observed at a Sakarya station (S7) (Ellsworth and Celebi, 1999). Bouchon et al. (2000) studied the source process by waveform inversion and found supershear rupture propagation at about $4.7 \mathrm{~km} / \mathrm{s}$ east of the hypocenter, extending over a length of about $45 \mathrm{~km}$ along the fault. Beyond this distance, rupture decelerates to about $3.1 \mathrm{~km} / \mathrm{s}$, while the westward propagation of rupture from the hypocenter occurs at an average rupture velocity of 

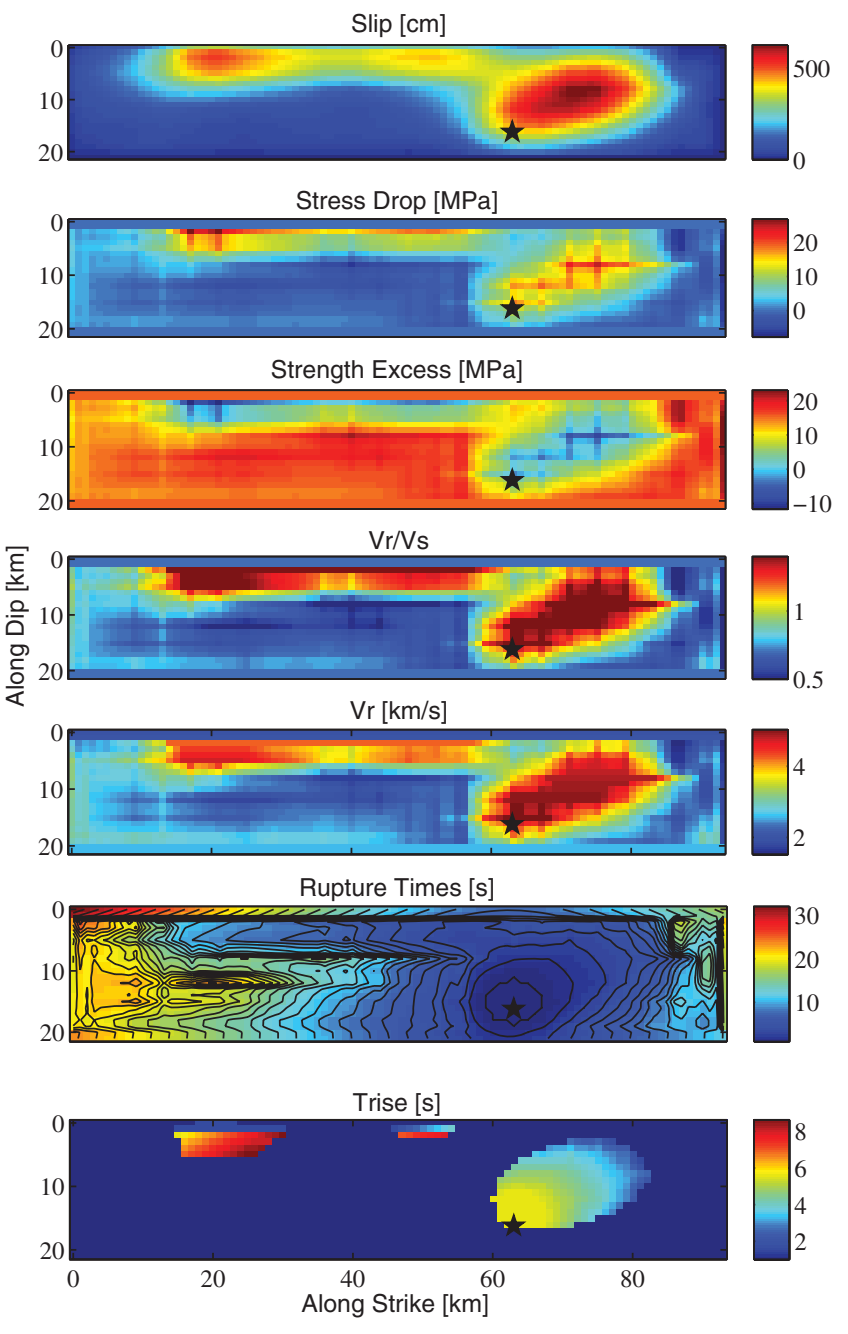

Figure 13. The new PD source model for the 1999 Izmit earthquake based on the slip inversion of Yagi and Kikuchi (2000). From top to bottom, the slip, stress drop, strength excess, the ratio of the rupture speed and the shear wave speed $\left(V_{r} / V_{S}\right)$, the rupture speed $\left(V_{r}\right)$, the corresponding rupture times and the rise time distributions are shown.

$3 \mathrm{~km} / \mathrm{s}$. The results from the waveform inversion of Bouchon et al. (2000) match with our PD source model estimation.

3. The residual maps give a clear picture on the improvements achieved by the proposed PD method. The mean residual for the Imperial Valley earthquake using the G04 method for the slip inversion model of Archuleta (1984) is 6.5, which is reduced to 4 using the PD relations provided in this paper. Similarly, the simulations with the G04 method using the slip inversion of Hartzell and Heaton (1983) have the mean residual of 2.81, which decreases to 1.8 with the new PD model. Likewise using the G04 method and the new PD approaches for the slip inversion of Zeng and Anderson (2000), the mean residual reduces from 8.0 to 1.75. For the 1999 Izmit earthquake of $M_{\mathrm{w}} 7.7$, the mean residuals for the G04 method and the new PD model are 2.67 and 1.55, respectively. The details of the ground-motion synthetics, in comparison with the recordings, can be seen in the Appendix. We obtain clearly better-fitting synthetic ground motions confirmed, quantitatively by the residual comparisons. However, we did not perform a sensitivity analysis to identify the exact reasons for the improved simulations, that is, we cannot explicitly state that the enhancements in ground-motion simulations are due to the changed rupture-speed distribution, or the improved rise-time distributions, or the Yoffe type slip-rate function in the new simulations. We believe that our progress is a result of the combination of all changes. On the other hand, one needs to test the individual effect of each source parameter on the resulting ground motions to evaluate their influence on the simulations. However, we argue that the proposed PD approach is a direct consequence of dynamic rupture computations, and therefore is well constrained for moderate-to-large size strike-slip earthquakes with a single or multiple asperity patches, including the parameterization of source complexities this is physically consistent with stochastic initial stress dynamic rupture simulations.

\section{Conclusions}

We generate spontaneous dynamic rupture simulations as the basis for developing new relationships for an improved PD approach for strike-slip earthquakes in the magnitude range from $M_{\mathrm{w}} 6.0$ to 8.0. Simple relations are derived to predict the slip-rate function parameterization and the temporal evolution of slip along the fault. We observe that, due to stress heterogeneity, localized supershear rupture velocities exist for all event sizes, although the average rupture speed remains subshear. We also observe that the area that experience supershear rupture speeds increases with increasing earthquake size. Based on these simulations, we conjecture that local supershear rupture may prevail in nature. The main argument to this conclusion is that stress distribution on faults is highly heterogeneous.

We replace the Andrews (1976a) analytical formulation, used in the G04 method to compute rupture-speed distribution, to overcome the subshear rupture-speed limitation in our new set of PD relations based on stress heterogeneity. Our new relations are size dependent; that is, we define different relations based on the rupture length of the event. The proposed physics-based relations have the flexibility to allow for local supershear ruptures. We also find that the shape of the slip-rate functions is consistent with the Yoffe function (Tinti et al., 2005) within areas of high slip. Surrounding these areas, more complex functions are observed. We therefore parameterized the slip-rate function based on dynamically derived rise times $\tau_{r}$ and acceleration times $T_{\text {acc }}$ along the fault. We show that PD source modeling leads to a realistic representation of ground-motion time histories and has the potential to provide an improved physics-based source model characterization for strike-slip earthquakes over a wide magnitude range. Because the PD procedure 

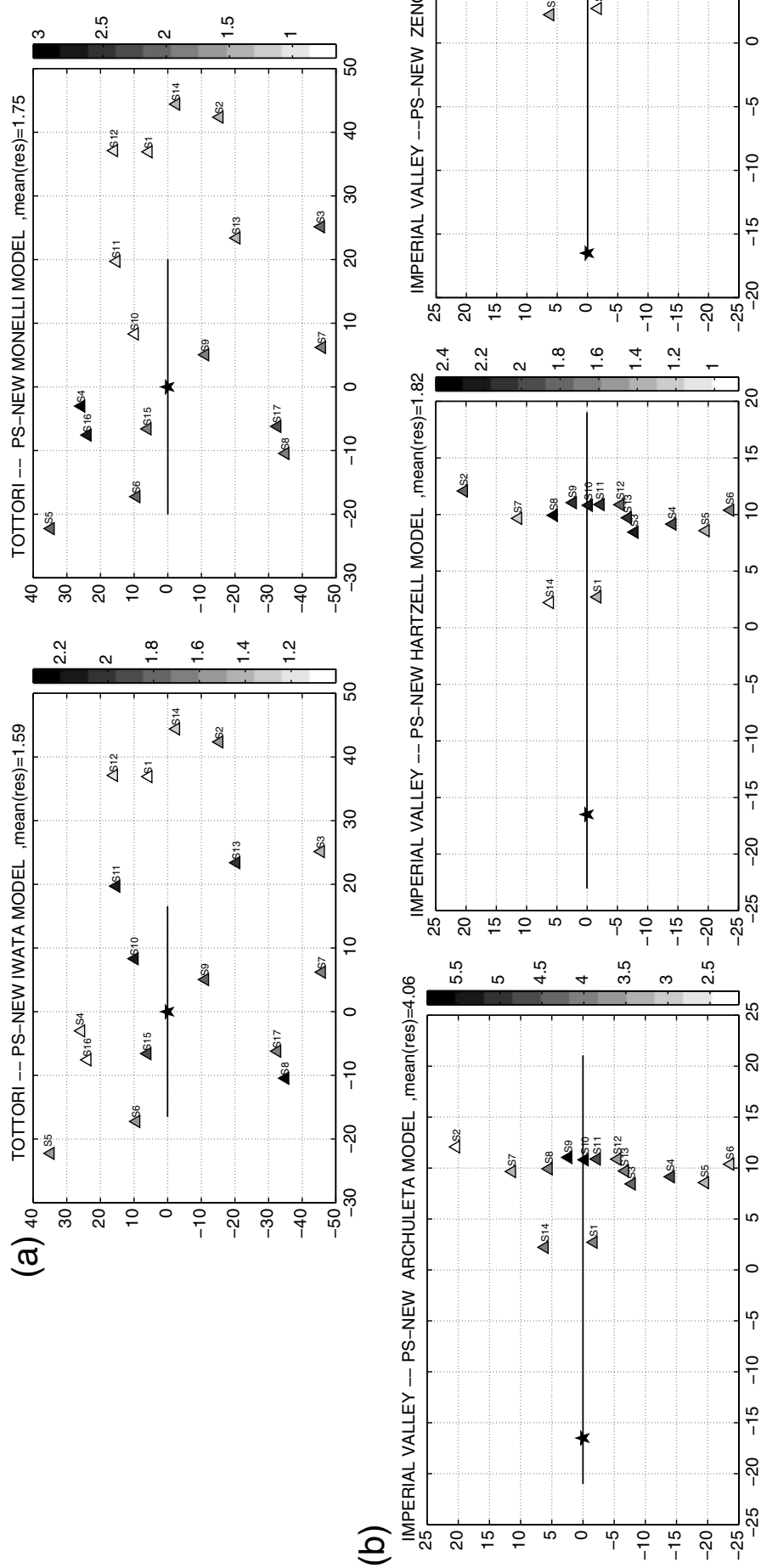

흘
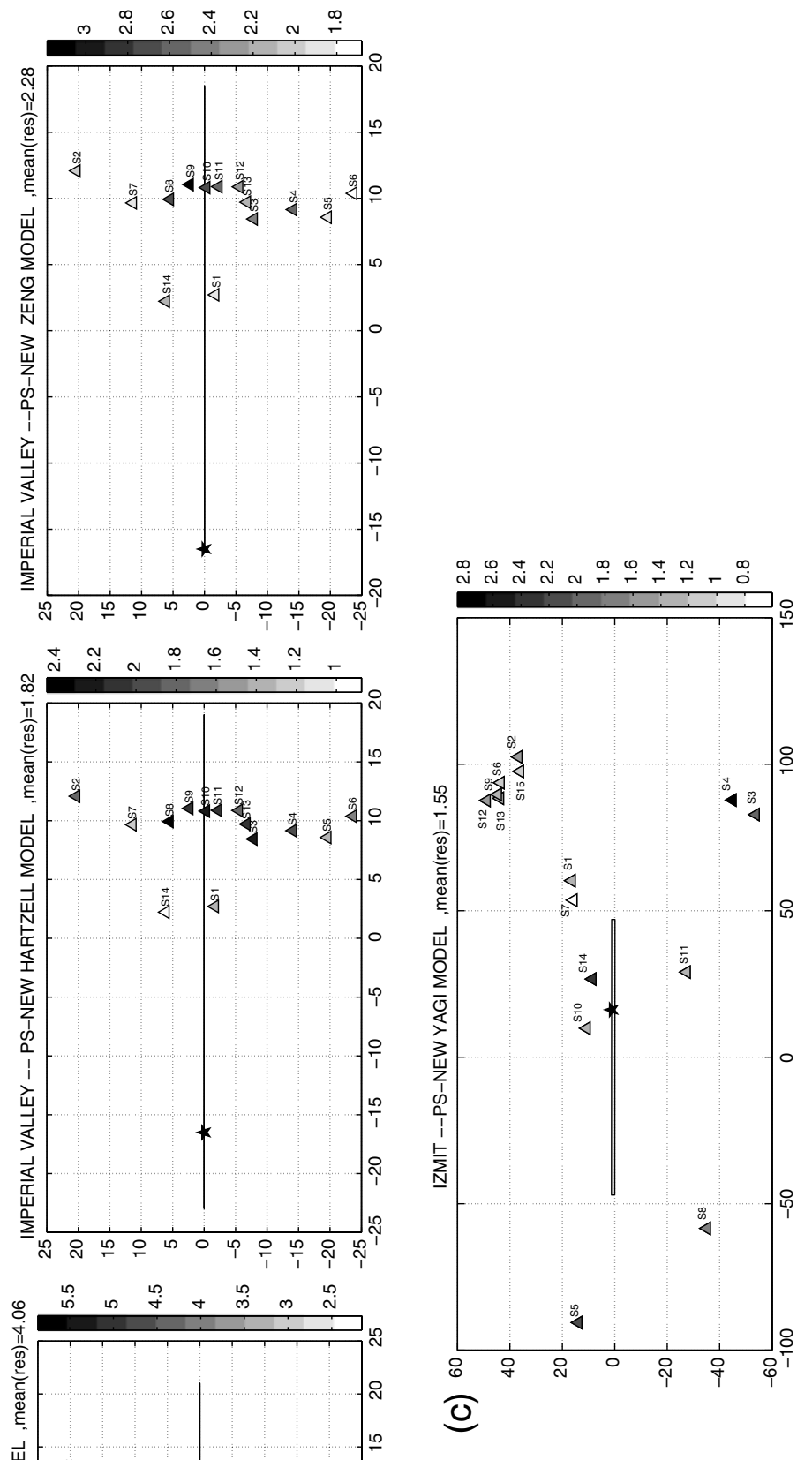

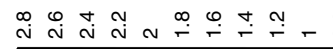

ํㅗㄹ

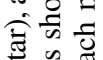

के

릉

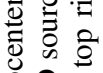

80

管

踏

की

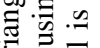

E

音

言 寻

:

ธี ํㅗㅇ

氙

氙 है

옹

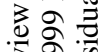

列

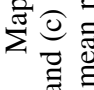

过

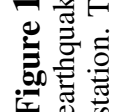


Table 2

Mean Residuals for Tottori, Imperial Valley, and Izmit Earthquake Simulations Using Different Slip Models and Using the G04 and the New PD Source Characterizations

\begin{tabular}{lcc}
\hline Model Name & Mean Residual (G04) & Mean Residual (New PD) \\
\hline Tottori-Iwata & 2.67 & 1.55 \\
Tottori-Monelli & 2.58 & 1.59 \\
Imp Val-Archuleta & 1.88 & 1.75 \\
Imp Val-Hartzell & 6.5 & 4.06 \\
Imp Val-Zeng & 2.81 & 1.82 \\
Izmit & 8.0 & 2.28 \\
\hline
\end{tabular}

proposed in this paper focuses on strike-slip earthquakes, future work should involve dynamic simulations of normal and thrust faulting events.

Difficulties arise when trying to accurately measure rise times in low slip areas. However, our tests with different constant rise-time values in background low slip areas reveal insignificant differences in the corresponding ground motions, suggesting that the low-slip background regions contribute negligibly to the seismic radiation. Further analysis may involve tests using different slip-rate functions for the background areas, or may establish a new rise-time definition and a new slip-rate function for the low slip areas. Another poorly constrained parameter in our PD model is the acceleration time of the Yoffe type slip-rate function. In using constant $T_{\text {acc }}$, we examine values between 0.1 and $0.3 \mathrm{~s}$, as advised by Tinti et al. (2005). Although our low-frequency simulations do not show notable changes, for high-frequency simulations this parameter may be of more importance. In addition, our dynamic simulations show a heterogeneous $T_{\text {acc }}$ distribution rather than a constant value, which can be parameterized, based on the slip-weakening distance $\left(D_{c}\right)$. Studying dynamic models with nonhomogeneous $D_{c}$ may provide new PD relations, leading to a better-constrained $T_{\text {acc }}$ distribution. This may not contribute much to the low-frequency synthetics, but may be more critical for the application of the PD approach to high-frequency simulations.

Our strike-slip dynamic simulations extend up to $100 \mathrm{~km}$ rupture length and show the tendency of increasing average rupture velocity with increasing earthquake size. It will be interesting to analyze the behavior of rupture velocity by including events of even longer rupture lengths $(L>100 \mathrm{~km})$. The proposed set of PD relations are validated for ground-motion simulations against real earthquakes of different sizes; however, validation of the results for events outside the magnitude range of this work needs to be carried out prior to applying the method to different category earthquakes.

\section{Data and Resources}

Observed strong ground-motion records used in this study were collected from the COSMOS Virtual Data Center. The data can be downloaded from http://db.cosmos-eq.org/ scripts/default.plx (last accessed September 2009). Source slip inversion data were collected from the Finite-Source Rupture Model Database at http://www.seismo.ethz.ch/ static/srcmod/ (last accessed April 2010). Data on the Zeng method from Zeng and Anderson (2000) are available at http://peer.berkeley.edu (last accessed March, 2010).

\section{Acknowledgments}

We would like to thank the two reviewers of the paper, Nelson Pulido and Arben Pitarka, and Associate Editor David D. Oglesby for constructive comments and very helpful reviews that led to improvements in the paper. This study was funded by the Swiss National Science Foundation (SNF), for Collaborative Project MERCI (Management of Earthquake Risks Using the Condition Indicators) under contract 200020-112326, SNF Grant NF 200021-118091, PD-GMsim and SCEC Grant 07111 from the Southern California Earthquake Center (funded through the NSF Cooperative Agreement Number EAR-0106924 and USGS Cooperative Agreement Number 02HQAG0008). Some of the simulations were done at the Swiss National Supercomputing Center (CSCS), under the production project "Development of Dynamic Rupture Models to Study the Physics of Earthquakes and Near-Source Ground Motion.'

\section{References}

Aagaard, B. T., T. M. Brocher, D. Dolenc, D. Dreger, R. W. Graves, S. Harmsen, S. Hartzell, S. Larsen, and M. L. Zoback (2008). Ground-motion modeling of the 1906 San Francisco earthquake, Part I: Validation using the 1989 Loma Prieta earthquake, Bull. Seismol. Soc. Am. 98, no. 2, 989-1011.

Andrews, D. J. (1976a). Rupture propagation with finite stress in antiplane strain, J. Geophys. Res. 81, 3575-3582.

Andrews, D. J. (1976b). Rupture velocity of plane-strain shear cracks, $J$. Geophys. Res. 81, 5679-5687.

Andrews, D. J. (1980). A stochastic fault model, 1, static case, J. Geophys. Res. 85, 3867-3877.

Archuleta, R. J. (1984). A faulting model for the 1979 Imperial Valley earthquake, J. Geophys. Res. 89, no. B6, 4559-4585.

Beeler, N. M., T. E. Tullis, and D. L. Goldsby (2008). Constitutive relationships and physical basis of fault strength due to flash heating, J. Geophys. Res. 113, B01401, doi 10.1029/2007JB004988.

Beroza, G. C. (1991). Near-source modeling of the Loma-Prieta earthquake: Evidence for heterogeneous slip and implications for earthquake hazard, Bull. Seismol. Soc. Am. 81, no. 5, 1603-1621.

Beroza, G. C., and T. Mikumo (1996). Short slip duration in dynamic rupture in the presence of heterogeneous fault properties, J. Geophys. Res. 101, 449-460.

Bizzarri, A., and P. Spudich (2008). Effects of super-shear rupture speed on the high frequency content of $S$-waves investigated using spontaneous dynamic rupture models and isochrone theory, J. Geophys. Res. 113, doi 10.1029/2007JB005146.

Bouchon, M., and M. Vallée (2003). Observation of long supershear rupture during the magnitude 8.1 Kunlunshan earthquake, Science 301, no. $5634,824-826$.

Bouchon, M., N. Toksöz, H. Karabulut, M.-P. Bouin, M. Dietrich, M. Aktar, and M. Edie (2000). Seismic imaging of the 1999 Izmit (Turkey) rupture inferred from the near-fault recordings, Geophys. Res. Lett. 27, 3013-3016.

Burridge, R., G. Conn, and L. B. Freund (1979). Stability of a rapid mode II shear crack with finite cohesive traction, J. Geophys. Res. 84, no. NB5, 2210-2222.

Byerlee, J. (1978). Friction of rocks, Pure Appl. Geophys. 116, 615-626.

Dalguer, L. A., and S. M. Day (2007). Staggered-grid split-node method for spontaneous rupture simulation, J. Geophys. Res. 112, (B02302), doi 10.1029/2006JB004467. 
Dalguer, L. A., H. Miyake, S. M. Day, and K. Irikura (2008). Surface rupturing and buried dynamic rupture models calibrated with statistical observations of past earthquakes, Bull. Seismol. Soc. Am. 98, 11471161.

Das, S., and K. Aki (1977). Fault planes with barriers: A versatile earthquake model, J. Geophys. Res. 82, 5648-5670.

Day, S. M. (1982a). Three-dimensional finite difference simulation of fault dynamics: Rectangular faults with fixed rupture velocity, Bull. Seismol. Soc. Am. 72, 705-727.

Day, S. M. (1982b). Three-dimensional simulation of spontaneous rupture: The effect of nonuniform prestress, Bull. Seismol. Soc. Am. 72, 18811902.

Day, S. M., L. A. Dalguer, N. Lapusta, and Y. Liu (2005). Comparison of finite difference and boundary integral solutions to three-dimensional spontaneous rupture, J. Geophys. Res. 110, B12307, doi 10.1029/ 2005JB003813.

Day, S. M., G. Yu, and D. J. Wald (1998). Dynamic stress changes during earthquake rupture, Bull. Seismol. Soc. Am. 88, no. 2, 512-522.

Dieterich, J. H. (1979). Modeling of rock friction 1. Experimental results and constitutive equation, J. Geophys. Res. 84, 2161-2168.

Dietz, L. K., and W. L. Ellsworth (1990). The October 17, 1989, Loma Prieta, California, earthquake and its aftershocks: Geometry of the sequence from high-resolution locations, Geophys. Res. Lett. 17, 1417-1420.

Dunham, E. M. (2007). Conditions governing the occurrence of supershear ruptures under slip-weakening friction, J. Geophys. Res. 112, (B07302), doi 10.1029/2006JB004717.

Ellsworth, W. L., and M. Celebi (1999). Near field displacement time histories of the $M 7.4$ Kocaeli (Izmit), Turkey, earthquake of August 17, 1999, Eos Trans. AGU, 80, 46, F648.

Ely, G., S. M. Day, and J-B. Minster (2010). Dynamic rupture models for the southern San Andreas fault, Bull. Seismol. Soc. Am. 100, 131-150, doi 10.1785/0120090187.

Fuis, G. S., W. D. Mooney, J. H. Healey, G. H. McMechan, and W. J. Lutter (1981a). Seismic refraction studies of the Imperial Valley region, California-Profile models, a travel time contour map, and a gravity model, U.S. Geol. Surv. Open-File Rept. 81-270, 72 pp.

Fuis, G. S., W. D. Mooney, J. H. Healey, G. H. McMechan, and W. J. Lutter (1981b). Crustal structure of the Imperial Valley region, U.S. Geol Surv. Profess. Paper 1254.

Graves, R., and A. Pitarka (2010). Broadband ground-motion simulation using a hybrid approach, Bull. Seismol. Soc. Am. 100, 2095-2123, doi 10.1785/0120100057.

Guatteri, M., M. P. Mai, G. C. Beroza, and J. Boatwright (2003). Strong motion prediction from stochastic-dynamic source models, Bull. Seismol. Soc. Am. 93, 301-313.

Guatteri, M., P. M. Mai, and G. C. Beroza (2004). A PD approximation to dynamic rupture models for strong ground motion prediction, Bull. Seismol. Soc. Am. 94, 2051-2063.

Hanks, T. C., and W. H. Bakun (2003). A bilinear source-scaling model for $M-\log$ observations of continental earthquakes, Bull. Seismol. Soc. Am. 92, no. 5, 1841-1846.

Hartzell, S. H., and T. H. Heaton (1983). Inversion of strong ground motion and teleseismic waveform data for the fault rupture history of the 1979 Imperial Valley, California, earthquake, Bull. Seismol. Soc. Am. 73, $1553-1583$.

Heaton, T. H. (1990). Evidence for and implications of self-healing pulses of slip in earthquake rupture, Phys. Earth Planetary Interiors 64, 1-20.

Hisada, Y. (2000). A theoretical square model considering the spatial variation in slip and rupture velocity, Bull. Seismol. Soc. Am. 90, 387-400.

Iwata, T., and H. Sekiguchi (2001). Substance of the earthquake faulting during the 2000 western Tottori earthquake, SEISMO 5, March 2001, 5-7 (in Japanese).

Kagawa, T., K. Irikura, and P. Somerville (2004). Differences in ground motion and fault rupture process between surface and buried rupture earthquakes, Earth, Planets and Space 56, 3-14.

Kostrov, B. V. (1966). Unsteady propagation of longitudinal shear cracks, $J$. Appl. Math. Mech.30, 1241-1248.
Mai, P. M., and G. C. Beroza (2002). A spatial random-field model to characterize complexity in earthquake slip, J. Geophys. Res. 107, no. B11, 2308, doi 10.1029/2001JB000588.

Mai, P. M., M. Guatteri, G. C. Beroza, and J. Boatwright (2001). Toward a more physical basis for strong-motion simulation, Seismol. Res. Lett. 72, 273.

Mai, P. M., P. Spudich, and J. Boatwright (2005). Hypocenter locations in finite-source rupture models, Bull. Seismol. Soc. Am. 95, no. 3, 965-980.

Miyake, H., T. Iwata, and K. Irikura (2003). Source characterization for broadband ground-motion simulation: Kinematic heterogeneous source model and strong motion generation area, Bull. Seismol. Soc. Am. 93, 2531-2545, doi 10.1785/0120020183.

Monelli, D., P. M. Mai, S. Jonsson, and D. Giardini (2009). Bayesian imaging of the 2000 Western Tottori (Japan) earthquake through fitting of strong motion and GPS data, Geophys. J. Int. 176, 135-150.

Oglesby, D., and P. M. Mai (2012). Fault geometry, rupture dynamics and ground motion from potential earthquakes on the North Anatolian Fault under the Sea of Marmara, Geophys. J. Int. doi 10.1111/ j.1365-246X.2011.05289.x.

Ohnaka, M., Y. Kuwahara, and K. Yamamoto (1987). Constitutive relations between dynamic physical parameters near a tip of the propagating slip zone during stick-slip shear failure, Tectonophysics 144, 109-125.

Olsen, K. B., L. A. Dalguer, J. Mayhew, Y. Cui, J. Zhu, V. M. Cruz-Atienza, D. Roten, P. Maechling, T. H. Jordan, D. Okaya, and A. Chourasia (2009). ShakeOut-D: Ground motion estimates using an ensemble of large earthquakes on the southern San Andreas fault with spontaneous rupture propagation, Geophys. Res. Lett. 36, L04303, doi 10.1029/2008GL036832.

Olsen, K. B., S. M. Day, J. B. Minster, Y. Cui, A. Chourasia, M. Faerman, R. Moore, P. Maechling, and T. Jordan (2006). Strong shaking in Los Angeles expected from southern San Andreas earthquake, Geophys. Res. Lett. 33, L07305, doi 10.1029/2005GL025472.

Olsen, K. B., S. M. Day, J. B. Minster, Y. Cui, A. Chourasia, D. Okaya, P. Maechling, and T. Jordan (2008).TeraShake2: Simulation of $M_{\mathrm{w}} 7.7$ earthquakes on the southern San Andreas with spontaneous rupture description, Bull. Seismol. Soc. Am 98, 1162-1185.

Olsen, K. B., R. Madariaga, and R. Archuleta (1997). Three dimensional dynamic simulation of the 1992 Landers earthquake, Science 278, 834-838.

Pulido, N., and L. A. Dalguer (2009). Estimation of the high-frequency radiation of the 2000 Tottori (Japan) earthquake based on a dynamic model of fault rupture: Application to the strong ground motion simulation, Bull. Seismol. Soc. Am. 99, no. 4, 2305-2322, doi 10.1785/ 0120080165 .

Rice, J. R., C. G. Sammis, and R. Parsons (2005). Off-fault secondary failure induced by a dynamic slip pulse, Bull. Seismol. Soc. Am. 95, 109-134.

Ripperger, J., J. P. Ampuero, P. M. Mai, and D. Giardini (2007). Earthquake source characteristics from dynamic rupture with constrained stochastic fault stress, J. Geophys. Res. 112, B04311, doi 10.1029/2006JB004515.

Rojas, O., E. Dunham, S. M. Day, L. A. Dalguer, and J. Castillo (2009). Finite difference modelling of rupture propagation with strong velocity-weakening friction, Geophys. J. Int. 179, 1831-1858, doi 10.1111/j.1365-246X.2009.04387.x.

Ruina, A. L. (1983). Slip instability and state variable friction laws, J. Geophys. Res. 88, 10359-10370.

Schmedes, J., R. J. Archuleta, and D. Lavallée (2010). Correlation of earthquake source parameters inferred from dynamic rupture simulations, $J$. Geophys. Res. 115, B03304, doi 10.1029/2009JB006689.

Semmane, F., F. Cotton, and M. Campillo (2005). The 2000 Tottori earthquake: A shallow earthquake with no surface rupture and slip properties controlled by depth, J. Geophys. Res. 110, B03306, doi 10.1029/ 2004JB003194.

Somerville, P. G., and R. W. Graves (2003). Characterization of earthquake strong ground motion, Pure Appl. Geophys. 160, 1811-1828.

Somerville, P., K. Irikura, R. Graves, S. Sawada, D. Wald, N. Abrahamson, Y. Iwasaki, T. Kagawa, N. Smith, and A. Kowada (1999). Character- 
izing crustal earthquake slip models for the prediction of strong ground motion, Seismol. Res. Lett. 70, 59-80.

Song, S. G., and P. Somerville (2010). Physics-based earthquake source characterization and modeling with geostatistics, Bull. Seismol. Soc. Am. 100, no. 2, 482-496.

Spudich, P., and E. Cranswick (1984). Direct observation of rupture propagation during the 1979 Imperial Valley earthquake using a short baseline accelerometer array, Bull. Seismol. Soc. Am. 74, 2083-2114.

Spudich, P., and L. Xu (2003). Software package COMPSYN: Programs for earthquake ground motion calculation using complete 1-D Green's functions, in International Handbook of Earthquake \& Engineering Seismology, in International Geophysics Series, W. H. K. Lee, H. Kanamori, P. Jennings, and C. Kisslinger (Editors), Vol. 81, Academic Press, Amsterdam, The Netherlands.

Tinti, E., E. Fukuyama, A. Piatanesi, and M. Cocco (2005). A kinematic source-time function compatible with earthquake dynamics, Bull. Seismol. Soc. Am. 95, no. 4, 1211-1223.

Wald, D. J., D. V. Helmberger, and T. H. Heaton (1991). Rupture model of the 1989 Loma-Prieta earthquake from the inversion of strong-motion and broad-band teleseismic data, Bull. Seismol. Soc. Am. 81, no. 5, $1540-1572$.

Yagi, Y., and M. Kikuchi (2000). Source rupture process of the Kocaeli, Turkey, earthquake of August 17, 1999, obtained by joint inversion of near-field data and teleseismic data, Geophys. Res. Lett. 27, no. 13, 1969-1972.

Zeng, Y., and J. Anderson (2000). Evaluation of numerical procedures for simulating near-fault long-period ground motions using Zeng method. Report 2000/01 to the PEER Utilities Program.

\section{Appendix}

The following figures show the simulated ground motions plotted in red, on top of recorded ground motions at a number of sites for the G04 method and the new PD source models. Figures A1 and A2 illustrate the waveform comparisons for the 2000 Tottori earthquake, using the G04 method and the new PD approaches respectively. Figures A3 and A4 display the waveform comparisons for the 1979 Imperial Valley earthquake, using the G04 method and the new PD approaches, respectively. Figures A5 and A6 display the waveform comparisons for the 1999 Izmit earthquake, using the G04 method and the new PD approaches, respectively.
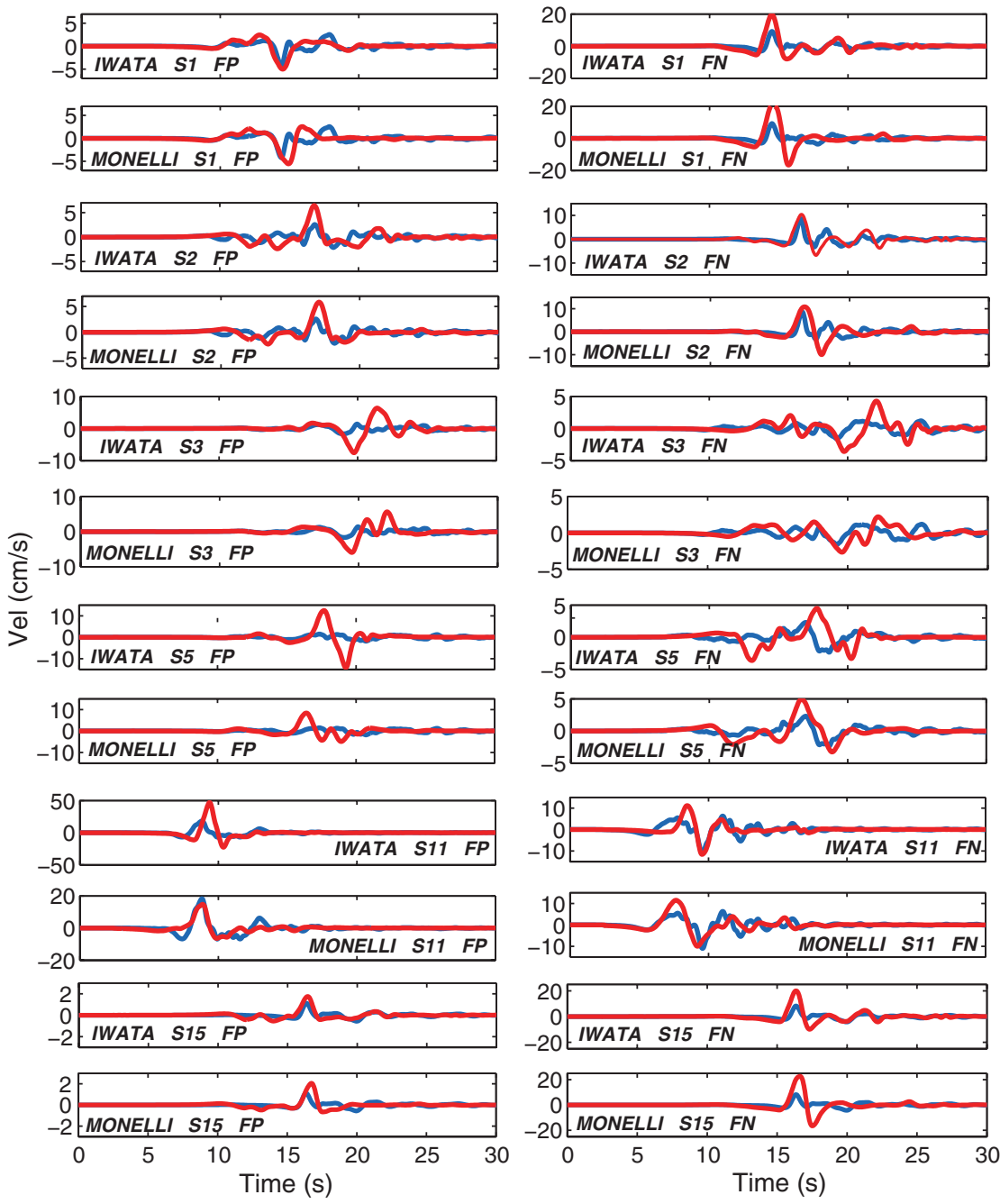

Figure A1. The synthetics plotted on top of recordings for the 2000 Tottori earthquake using the G04 source characteriztion shown in Figure 1, at several stations shown on the map in Figure 5a. The recorded ground motions are shown in blue; the synthetics are plotted in red. FP, fault parallel component; FN, fault normal component. 

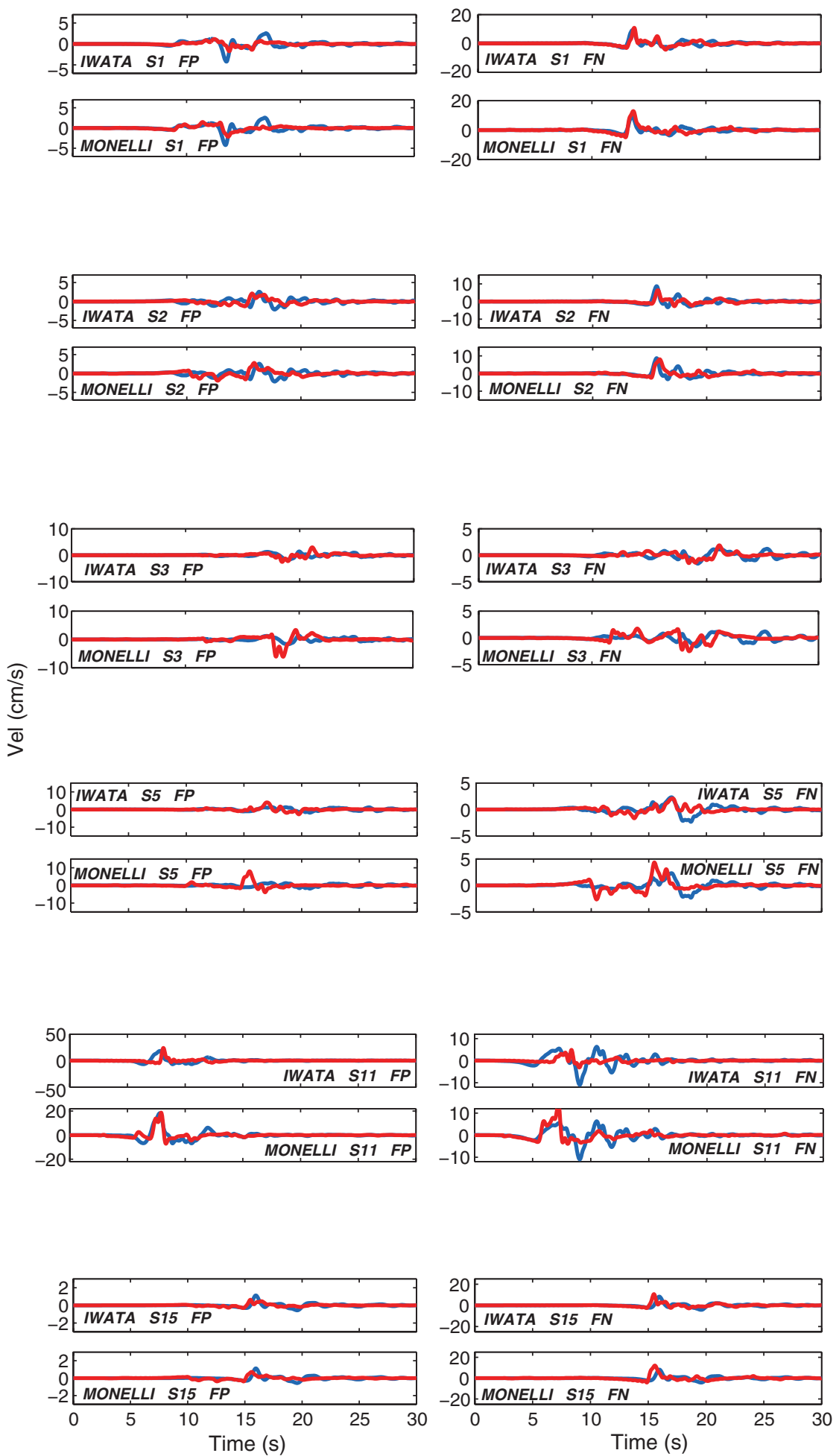

Figure A2. The synthetics plotted on top of recordings for the 2000 Tottori earthquake using the new PD source models shown in Figure 11, at several stations shown on the map in Figure 5a. The recorded ground motions are shown in blue; the synthetics are plotted in red. FP, fault parallel component; FN, fault normal component.

As seen from Figure A1, the synthetics match fairly well with the simulations, although we obtain slight improvements in Figure A2. The waveform fits in Figure A3 are poorer, and significant underpredictions are observed, while the new PD method shows large improvements in Figure A4. The simulations for the Izmit earthquake illustrated in 

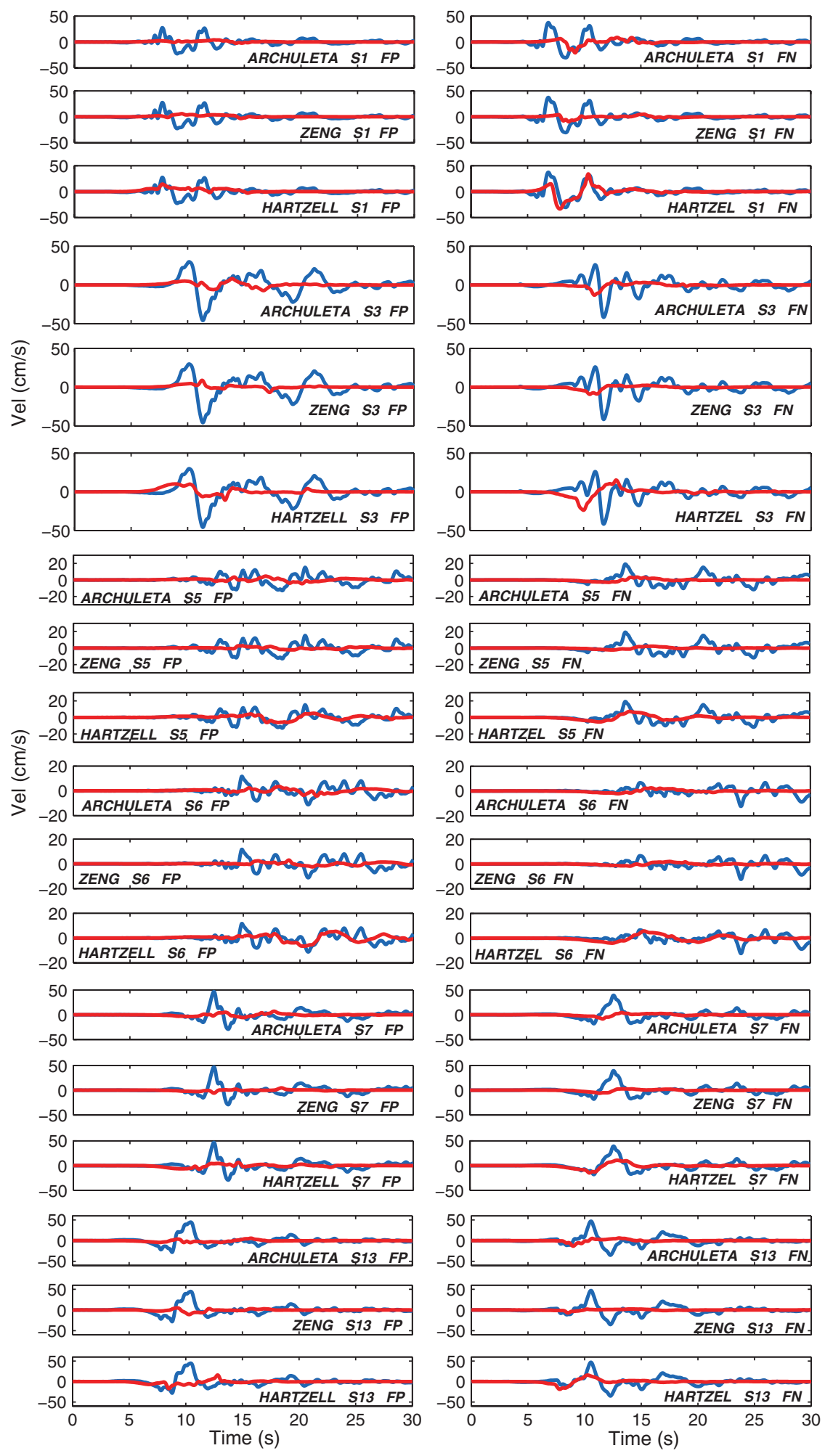

Figure A3. The synthetics plotted on top of recordings for the 1979 Imperial Valley earthquake using the G04 source characterization shown in Figure 3, at several stations shown on the map in Figure 5c. The recorded ground motions are shown in blue; the synthetics are plotted in red. FP, fault parallel component; FN, fault normal component. 

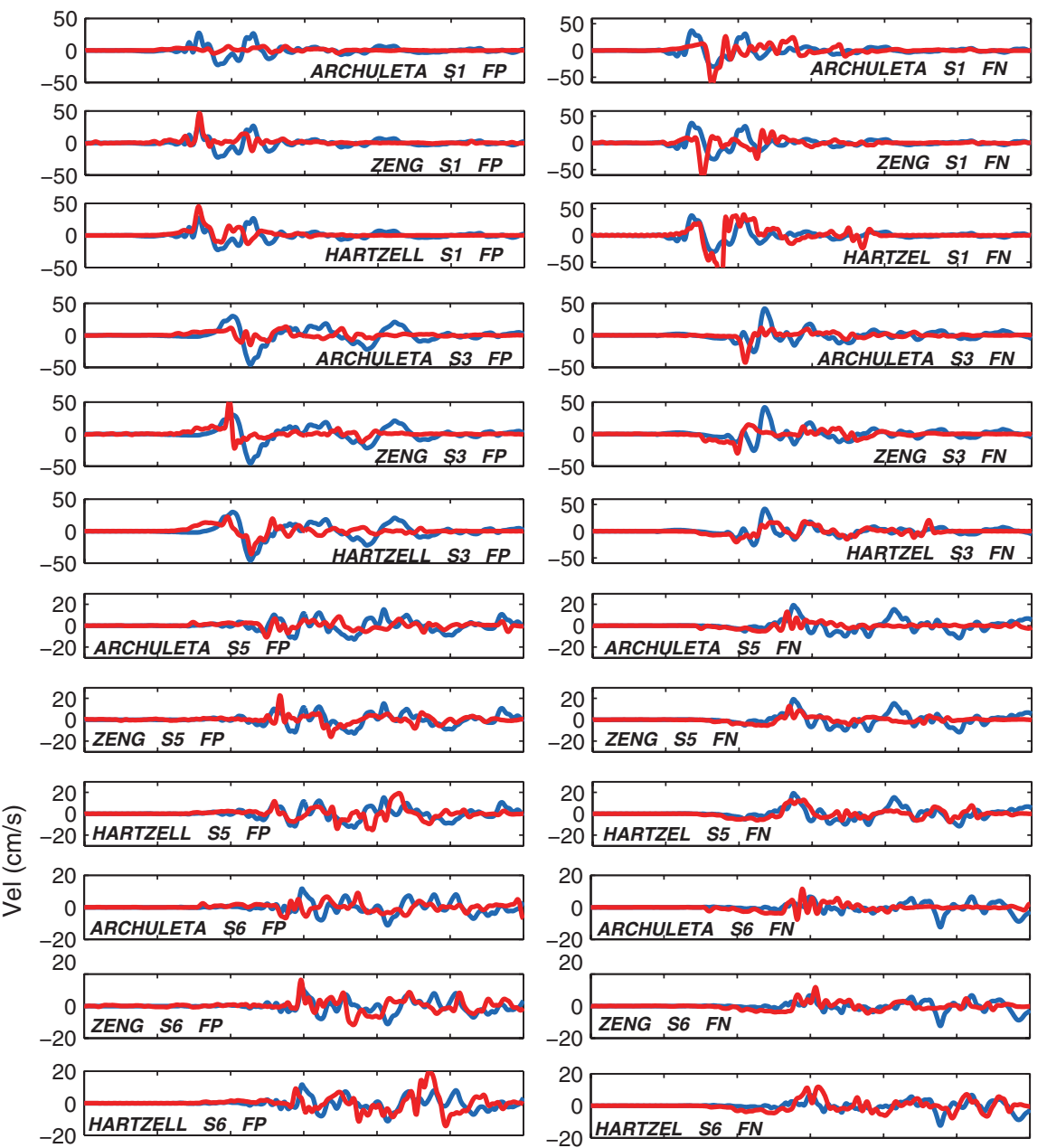
20
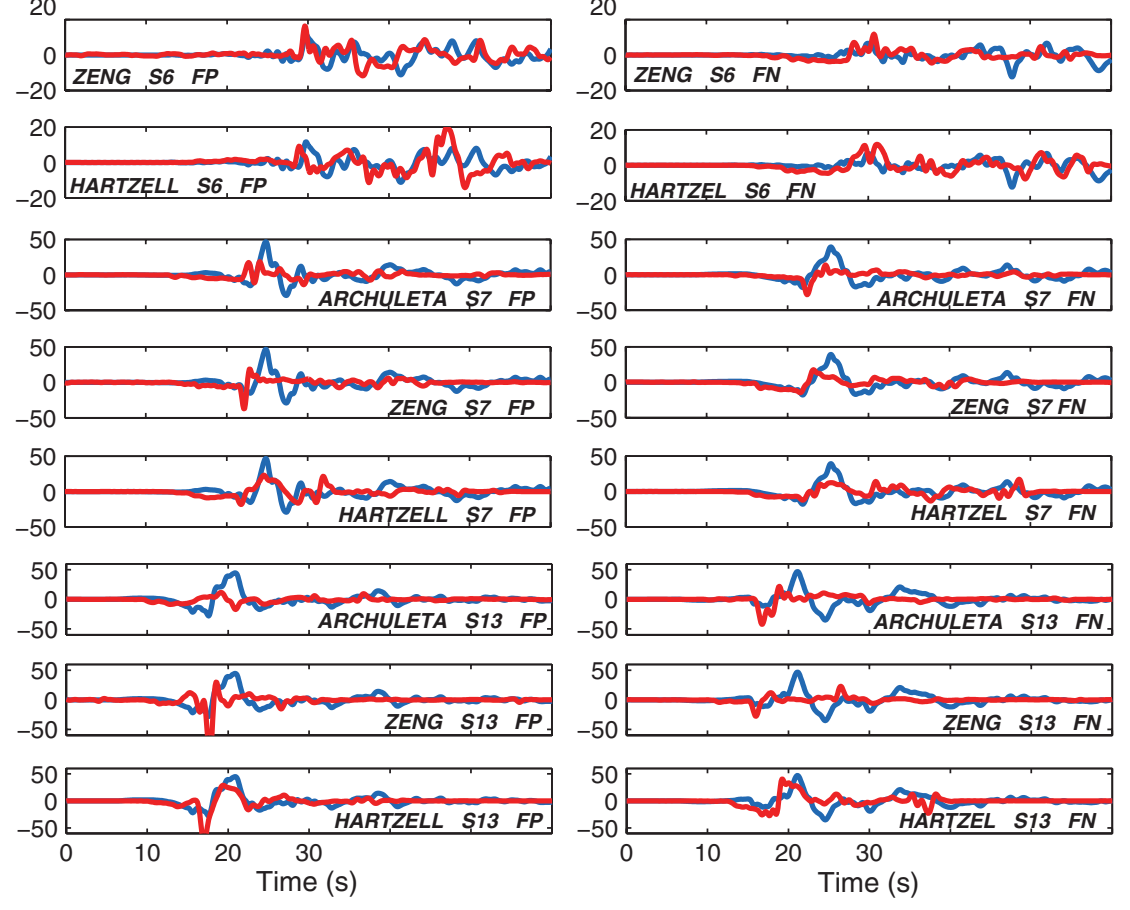

Figure A4. The synthetics plotted on top of recordings for the 1979 Imperial Valley earthquake using the new PD source characterization shown in Figure 12, at several stations shown on the map in Figure 5c. The recorded ground motions are shown in blue; the synthetics are plotted in red. FP, fault parallel component; FN, fault normal component. 

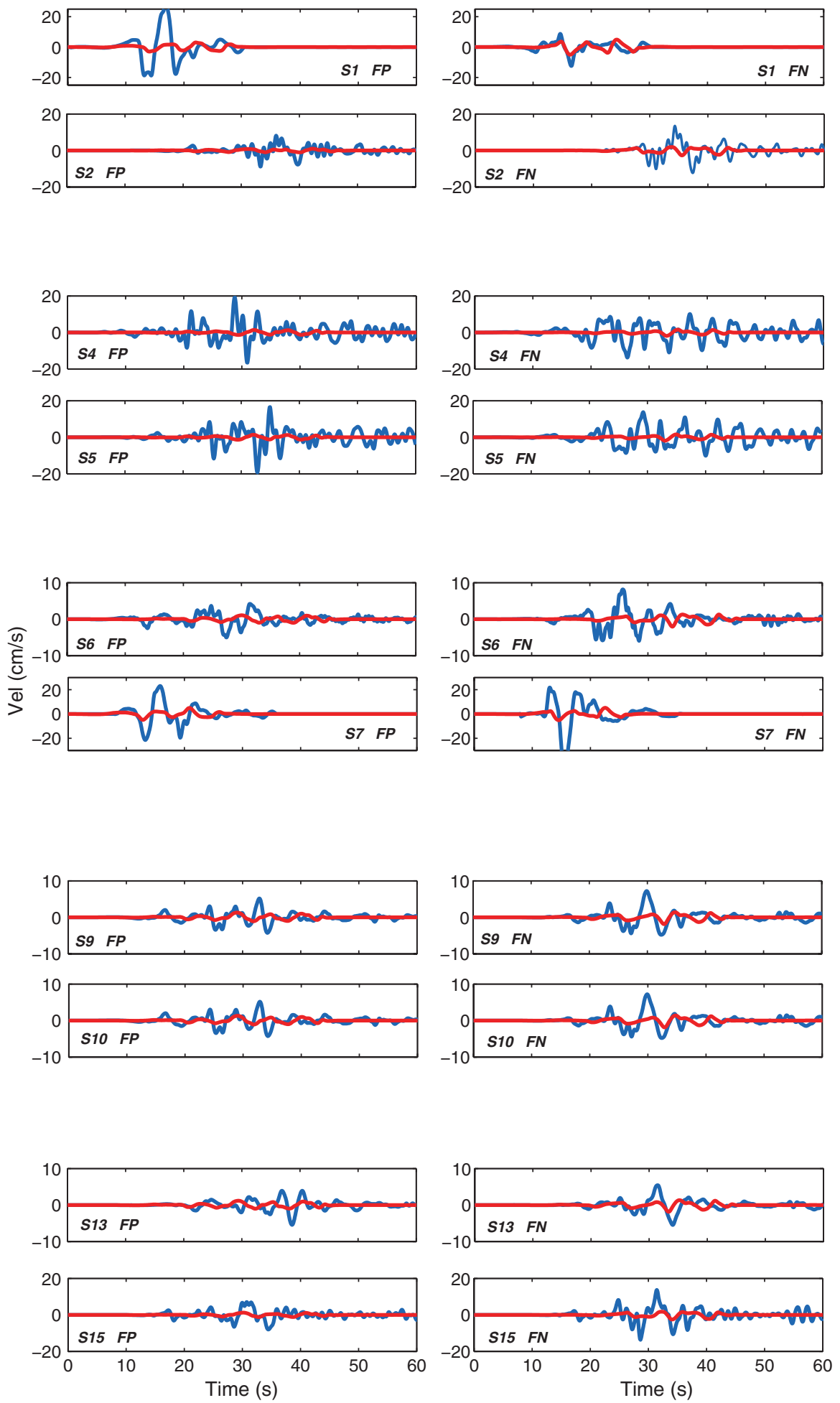

Figure A5. The synthetics plotted on top of recordings for the 1999 Izmit earthquake using the G04 source characterization shown in Figure 4, at the stations shown on the map in Figure 5d. The recorded ground motions are shown in blue; the synthetics are plotted in red. FP, fault parallel component; FN, fault normal component. 

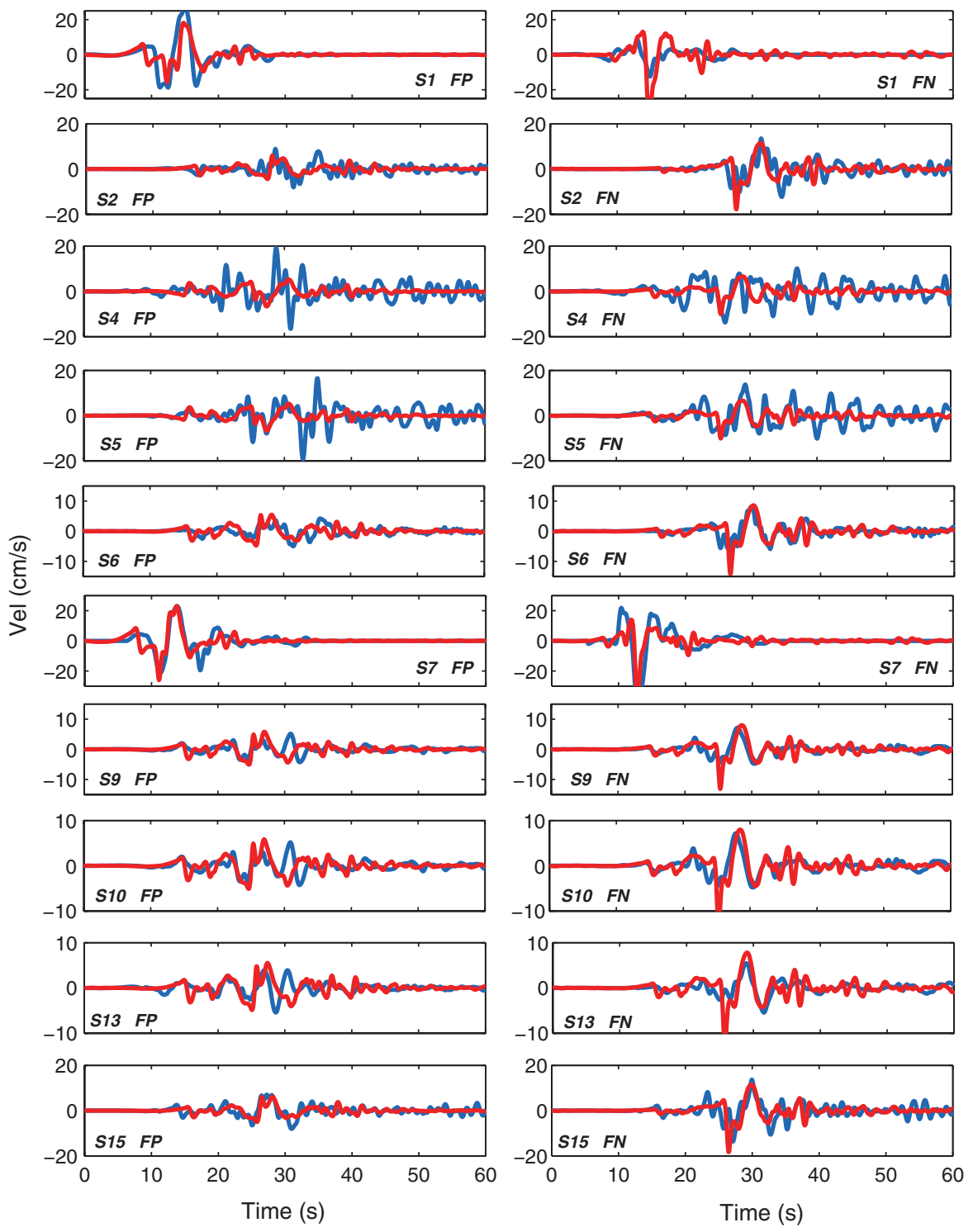

Figure A6. The synthetics plotted on top of recordings for the 1999 Izmit earthquake using the new PD source characterization shown in Figure 13, at the stations shown on the map in Figure 5d. The recorded ground motions are shown in blue; the synthetics are plotted in red. FP, fault parallel component; FN, fault normal.

Figure A5 are insufficient. The simulated ground motions are much lower in amplitude than the recorded ground motions, and the waveforms are incomparable. Figure A6 shows remarkable improvements in the waveform fits for the Izmit earthquake.
King Abdullah University of Science and Technology (KAUST)

Division of Physical Sciences and Engineering

Thuwal 23955-6900

Saudi Arabia

(P.M.M.)

Swiss Seismological Service

ETH Zurich

Sonneggstrasse 5

CH-8092 Zurich Switzerland

dalguer@sed.ethz.ch

banu.sanli@sed.ethz.ch

(B.M., L.A.D.) 